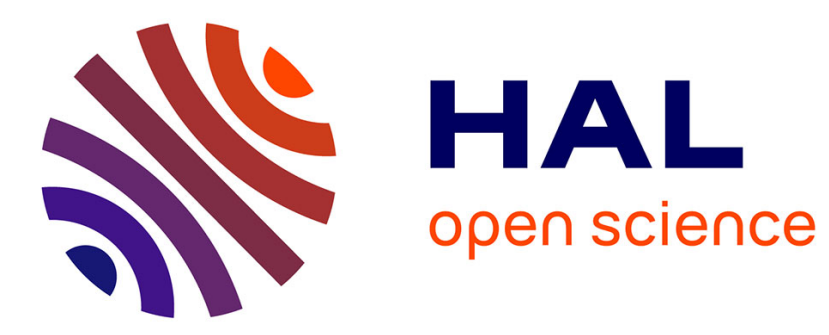

\title{
What drives markups? Evolutionary pricing in an agent-based stock-flow consistent macroeconomic model
}

Pascal Seppecher, Isabelle Salle, Marc Lavoie

\section{To cite this version:}

Pascal Seppecher, Isabelle Salle, Marc Lavoie. What drives markups? Evolutionary pricing in an agent-based stock-flow consistent macroeconomic model. 2018. hal-01486597v2

\section{HAL Id: hal-01486597 \\ https://hal.science/hal-01486597v2}

Preprint submitted on 13 Jun 2018

HAL is a multi-disciplinary open access archive for the deposit and dissemination of scientific research documents, whether they are published or not. The documents may come from teaching and research institutions in France or abroad, or from public or private research centers.
L'archive ouverte pluridisciplinaire HAL, est destinée au dépôt et à la diffusion de documents scientifiques de niveau recherche, publiés ou non, émanant des établissements d'enseignement et de recherche français ou étrangers, des laboratoires publics ou privés. 
This is a working paper version of an article published in Industrial and Corporate Change. The version of record is available online at: http://dx. doi.org/10.1093/icc/dty011. 


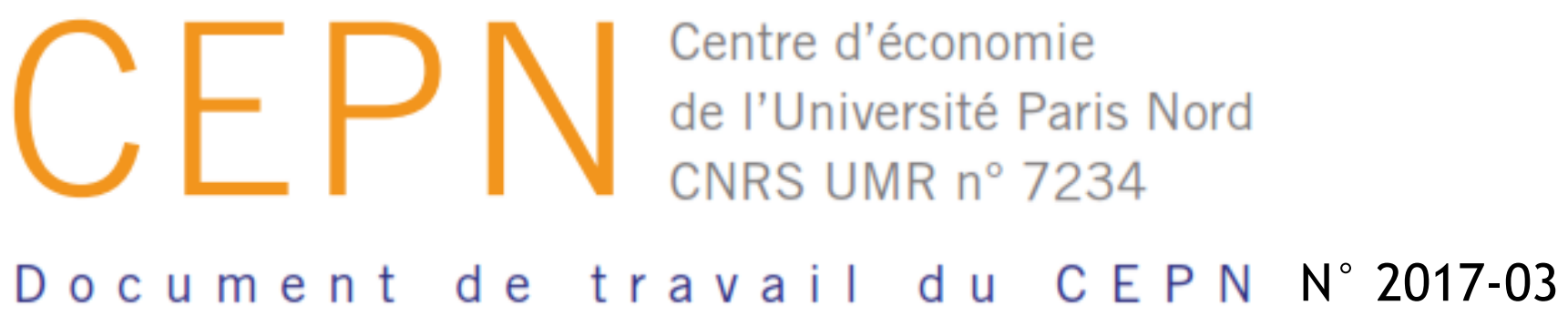

\title{
What drives markups? \\ Evolutionary pricing in an agent-based stock-flow consistent macroeconomic model
}

\author{
Pascal Seppecher, CEPN, Université de Paris 13 et CNRS \\ Isabelle L. Salle, Utrecht University, School of Economics \\ Marc Lavoie, CEPN, Université de Paris 13 et CNRS
}

\begin{abstract}
This paper studies coordination between firms in a multi-sectoral macroeconomic model with endogenous business cycles. Firms are both in competition and interdependent, and set their prices with a markup over unit costs. Markups are heterogeneous and evolve under market pressure. We observe a systematic coordination within firms in each sector, and between each sector. The resulting pattern of relative prices are consistent with the labor theory of value. Those emerging features are robust to technology shocks.
\end{abstract}

Keywords: General interdependence, Pricing, Agent-based modeling, Learning JEL Codes: C63; D46; E12; L11; L16. 
The most important subjects which economics seeks to investigate are ones which concern systems of many firms, or of all firms, which require consideration not only of how all firms, individually, behave, but also of how their individual activities interact and constrain each other, in markets, broad sectors and the whole economy.

(Wood 1971, p. 38)

\section{Introduction}

Markup, or cost-plus pricing, is a convenient pricing heuristic in making what would otherwise be complex and difficult decisions in a world of uncertainty (Lavoie 1992, p. 134). It is widely used in the industrial organization and macroeconomic literature, both in DSGE models and agent-based models (hereafter ABMs), and it finds strong empirical support (starting from the early and most famous work of Hall \& Hitch (1939); see Fabiani et al. (2006) for a survey in the Euro area for instance).

In most macroeconomic models, markups are an exogenous constant set over the marginal costs of firms under monopolistic competition, where market power stems from the preferences of consumers over differentiated goods - see Dixit \& Stiglitz (1977), Rotemberg \& Woodford (1999) who provide an extensive discussion of these models. In $\mathrm{ABMs}$, in line with the industrial organization literature, markups on unit costs often evolve with the firms' market shares (see e.g. Dosi et al. 2010). However, the problem of the determination of the level of the markup is not really solved, as the distribution law remains exogenous and supposes a centralized pricing mechanism.

In this paper, we take up the view that the pricing problem faced by the firms is non-trivial: increasing its markup allows the firm to increase its profit margins, but 
at the expense of its market share. Moreover, firms have to solve this trade-off in a situation of strategic uncertainty, especially once firms' heterogeneity is brought into the picture, as relative prices are relevant to assess market shares. Indeed, in a market economy, firms are both competitors and interdependent. Finally, firms' pricing decisions as a whole feed back into the macroeconomic dynamics, as they affect the distribution of income between the different sectors and agents, and therefore the level of aggregate demand. We do not hypothesize that there exists a simple solution to this complex coordination problem. Fully in tune with the best ABM approach, our solution is therefore not to guide the firms that populate our model, but let them explore as widely as possible the space of pricing strategies, observe whether market processes allow for a coordination and, if so, characterize which collective solution emerges.

In this paper, we seek to answer the following questions: in a market economy, which levels of markup can firms achieve? Do they differ between sectors and can we identify forces that drive their evolution?

Those questions lie in a broader perspective. The coordination problem faced by firms is a central question ever since A. Smith's metaphor of the "invisible hand". On the one hand, the division of labor reinforces the interdependence between all sectors; on the other, private ownership and individual initiative induce the fragmentation of production between competing units:

Indeed we must not forget that if the division of labour joins interests solidly together, it does not mix them together: it leaves them distinct, and in competition with one another (Durkheim 1984, p. 160).

Given such a contradiction, are markets able to coordinate the activity of a large number of interdependent and competing actors? Walrasian economics answers this question with an auctioneer. Neoclassical macroeconomics envisions the question 
through a fixed point reasoning, by computing optimal reaction functions and solving for equilibrium relative prices. In this paper, we contribute to this question without these strong assumptions, but by the use of a framework that is suited for tackling this problem in its complexity, namely an ABM.

ABMs are conceived to analyze out-of-equilibrium dynamics and adaptation processes from heterogeneous and interacting entities (see, e.g., Caiani, Russo, Palestrini \& Gallegati (2016) for an introduction to the AB approach). On a more specific note, we use a stock-flow consistent (hereafter, SFC) framework. Following Cincotti et al. (2010), Kinsella et al. (2011) and Seppecher (2012), there has been a multiplicity of macroeconomic models that combine two important features: the principle of decentralization/disaggregation which is found in ABM and the principle of stock-flow consistency formalized by Godley \& Lavoie (2007) (see Caverzasi \& Godin 2015 for a historical and theoretical account of the rapprochement between those two strands of the macroeconomic literature). In an ABM, macroeconomic variables are the result of a simple process of aggregation of individual data, as in the real word (Cohen 1960), so that the accounting accuracy provided by the SFC ensures the relevance of the aggregation process (Bruun 1999), as well as the interconnected nature of the balance sheets of all agents. Symmetrically, AB principles could provide micro-foundations to SFC macroeconomics, that is, a way to logically articulate and rigorously organize the interactions between the micro and the macro levels

An SFC-ABM appears as a tailored tool for the study of our research question. Disaggregation and heterogeneity are required to study coordination issues. Micro interactions are necessary to model market mechanisms and the endogenous emergence of aggregate patterns from those interactions. We model decentralization of both the goods and labor markets, on both the supply and the demand sides, which allows us to present a precise formalization of market competition and selection. For 
instance, firms set individually their prices and wages, so that the resulting wage rate and income distribution in the economy are endogenous. We further introduce evolutionary mechanisms that go hand in hand with heterogeneity and emerging behaviors under selection pressure. On this aspect, we rely on the evolutionary procedure developed in Alchian (1950), as it is best-suited for modeling the emergence of norms and customs under market competition. In our model, besides the standard decisions that firms need to take with regards to production and the management of their inventories, evolutionary mechanisms determine the markup levels and target leverage ratios. ${ }^{1}$ The selection of better strategies operates through market competition, so that strategies that lead to bankruptcy tend to be abandoned by the firms, while strategies that lead the firms to stay in the market tend to get diffused. Idiosyncratic shocks also constantly introduce innovations into firms' strategies, and provide them with adaptability in face of changes in the market conditions. We wish to stress that we do not rely on any ad-hoc selection operators, such as replicator dynamics, to emulate a selection pressure (see e.g. Dosi et al. 2016): in our model, the market mechanisms directly and "naturally" eliminate the unfitted behaviors. Furthermore, there is a macro closure which, besides modeling the financial and banking sectors, takes into account the aggregate demand arising from the behavior of households and resulting, at least partly, from the decisions taken by firms.

More precisely, we elaborate on the model of Seppecher et al. (2016) and its "leverage engine", which generates endogenous business cycles. We extend this model to a multi-sector economy, in which production and consumption involve three types of goods, in order to model an economy structured by strong interdependence relationships, both at the real and the monetary levels, between competing firms. While

\footnotetext{
${ }^{1}$ Our approach has affinities with the work by Silverberg \& Verspagen (1994), which has been one of the first to make a strategy of the firms (namely the share of $R \& D$ expenditures) endogenously evolve through a collective learning process. However, the selection mechanism is more parsimonious in our paper, as less fit strategies are simply abandoned when the firms go bankrupt.
} 
monetary interdependence, as explained above, is inspired by the works of Godley \& Lavoie (2007), real interdependence is inspired by Leontief $(1936,1937)$, Lowe (1952, 1955), Sraffa (1960), and more recently by Lee (2011) who presents models with several interdependent industrial sectors. Although there exists in the literature a few ABMs that exhibit both radical decentralization and stock-flow consistency ${ }^{2}$, we are not aware of any other ABM that also encompasses several interdependent production sectors. ${ }^{3}$ Some macroeconomic ABMs include only two sectors, a capital good sector and a consumption good sector, see e.g. Cincotti et al. (2010), Dosi et al. (2010), Dawid et al. (2014), Assenza et al. (2015) or Caiani, Godin, Caverzasi, Gallegati, Kinsella \& Stiglitz (2016). However, in these models, the capital good sector is oversimplified: it only employs labor and thus the production of capital goods is never limited by capacities. Furthermore, the question of relative prices and that of the emergence of an endogenous structure of sectoral markups are not studied.

The exercise that we conduct brings three main results. First, the overall economic system endogenously converges around a stationary state, average markups and gross profits do not fall to zero, but systematically stabilize at a strictly positive level.

Second, we observe intra-sectoral coordination between firms. The mechanism of market selection gives rise to the formation and the evolution of social norms such that firms are eventually constrained to use costing markups consistent with the literature on normal-cost pricing (Hall \& Hitch 1939, Lee \& Irving-Lessmann 1992, Coutts et al. 1978). According to this literature, prices are generically cost-plus prices, that is, prices depend on some standardized unit cost to which is added a

\footnotetext{
${ }^{2}$ See for instance (Seppecher 2012, Riccetti et al. 2015, Caiani, Godin, Caverzasi, Gallegati, Kinsella \& Stiglitz 2016).

${ }^{3}$ Note one exception, that of Mandel et al. (2015); however, the main assumptions of that model are such that it belongs to the tradition of neoclassical general equilibrium theory, and thus has no other link with our own model.
} 
costing margin. Consequently, prices are not set so as to insure the equality between supply and demand; instead they are perceived as reproduction prices, that is, prices that insure the reproduction of the system:

... custom and competition are predominant among the determinants of the mark-up for profit... whatever competitive factors affect the determination of the mark-up, the role of custom and convention is significant enough to place the motivation of the price administrators outside the simple description of maximizing profits... (Lee 1994, p. 325-326)

This post-Keynesian view is compatible with Simon's (1979) satisficing hypothesis, which denies that firms set prices in an attempt to maximize profits, but instead follow simple rules of thumb, or routines (see also Nelson \& Winter 1982 and the discussion in Mazzoleni \& Nelson 2013). Still, prices should cover unit labor and material costs, and generate a profit rate on the value of the financial capital required by firms. Our model shows that once the market competition and selection process does its work, this is precisely what happens. However, short-run fluctuations in prices and markups persist, as a result of the constant tension between seeking higher market shares and increasing profitability, complicated by a context of ever-changing market conditions.

Third, we observe inter-sectoral coordination: markup levels differ between sectors in a systematic way. This hierarchy of markups is driven by the production technology assumed in the model, insofar as the technology determines the real interdependence between firms in each of the three sectors. Most importantly, we found that the markups evolve so as to get relative prices in each sector to gravitate around their labor values, as hypothesized by the Classical school of thought.

Finally, our contribution in this paper shows that ABM approach provides not only useful tools to simulate macroeconomic dynamics with a high level of realism, but also decisive contributions to highly debated theoretical issues, such as the 
question of relative prices/pricing behaviors in market economies. Our paper is therefore also a proof-of-concept into that direction.

The rest of the paper is organized as follows: Section 2 describes the model, Section 3 provides the simulation protocol and our main hypotheses, Section 4 presents our results along our hypotheses, and Section 5 concludes.

\section{The model}

We now provide a general description of the model, focusing on the firms. Appendix B provides a detailed account of the timing of events within one period, including the exact behavioral rules used by every category of agents for every decision, as well as the initialization of all micro and macro variables.

\section{$2.1 \quad$ Structure}

The model is populated by a collection of heterogeneous firms, indexed by $j$ and heterogeneous households, indexed by $i$, as well as a bank. Figure 1 illustrates the structure of the model. At the beginning of any simulation, the firms are distributed between three industrial sectors: the intermediate goods sector (denoted as 'Sector 1' or S1), the consumption goods sector (denoted as 'Sector 2' or S2) and the investment goods sector (denoted as 'Sector 3' or S3).

There are two types of households: the 'workers' who supply labor to the firms, and the 'shareholders' who hold shares of the firms and receive dividends. Households, both workers when supplying labor or shareholders when buying shares, are indifferent between industrial sectors. The distribution of firms between the three sectors and households between the two types remains unchanged for the whole simulation.

All sectors need to combine machines with labor under constant returns to scale 


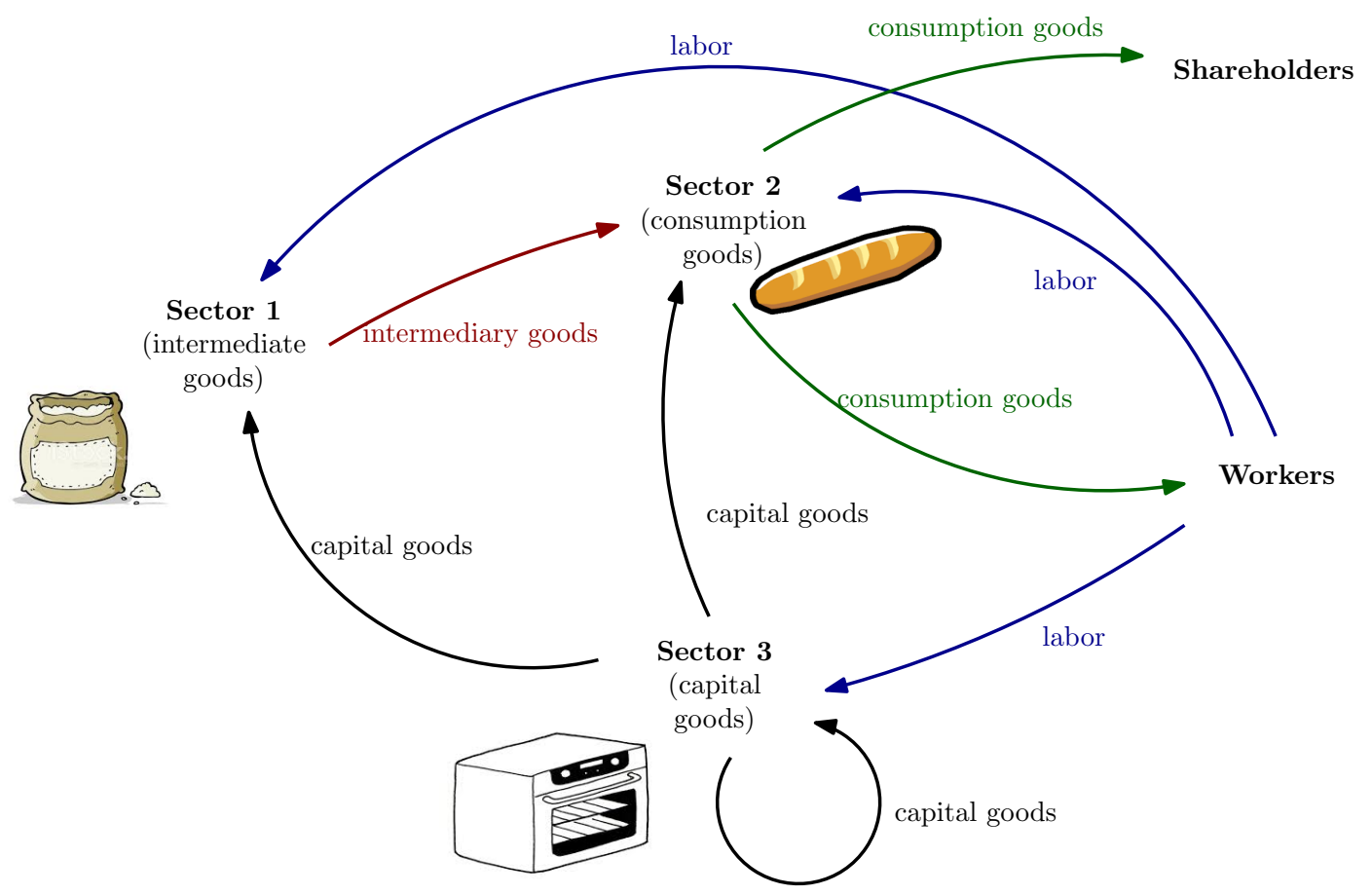

Figure 1 - Structure of real interactions

to produce goods. In every period and in every sector, one unit of labor has to be combined with one machine to result in production. All machines within a sector have the same, exogenously fixed, productivity. A fixed amount of investment goods (produced by S3) is required to be transformed into a machine. This amount of investment goods varies across the different sectors (see Table 7 in Appendix B.2), so as to allow for differentiated capital/workforce ratios across sectors. Thus, despite each machine being operated by one worker, by construction, the technical coefficients of each sector are different. Additionally, production in the consumption goods sector requires intermediate goods (see Table 1). Production in the model then consists of machines with labor producing investment goods (S3); machines with labor producing intermediate goods $(S 1)$; and machines with labor and intermediate goods producing consumption goods (S2).

One single bank stands for the whole banking and financial sector. This 'super- 


\begin{tabular}{lcc}
\hline \hline & Supply & Demand \\
\hline Intermediate goods & S1 & S2 \\
Consumption goods & S2 & Workers, Shareholders \\
Capital goods & S3 & S1, S2, S3 \\
\hline \hline
\end{tabular}

Table 1 - Real interdependence links

bank' provides loans to the firms to finance wages and investment, over an exogenously given number of periods at a risk-free interest rate that is set by a Taylor rule that targets consumer price inflation. It also hosts households' and firms' deposits (at a zero interest rate), allocates shareholders' excess cash to firms with excess leverage, and implements the foreclosure procedure for bankrupted firms.

\subsection{The firms}

Unless otherwise stated, all firms in all sectors have the same behavioral rules.

\subsubsection{Production plan}

Firms set both prices and quantities. We assume that firms set prices according to a markup over the unit cost of their goods. Unit costs include only the direct production costs, i.e., the wages and the costs of the intermediate goods that have been necessary to their production (it does not include the indirect costs such as interest payments or depreciation costs). Since firms carry inventories of produced but yet unsold products at each moment of time, one has to decide which unit cost will be the basis of the pricing procedure. We use the average unit direct cost, that is, the overall direct production cost of all the goods still in stock divided by the number of goods in the stock of inventories ${ }^{4}$.

The quantities to produce, and conversely the demand for labor, are set by gradual adjustments as a function of the firm's past sales, its production capacities and the

\footnotetext{
4 Thus, here, what we have is the historic direct unit cost of the goods in inventories (Godley \& Lavoie 2007, p. 266).
} 
level of its inventories. Furthermore, we assume that the firms in 52 keep a buffer stock of intermediate goods.

Additionally, the firms set their wage offer. The wage setting procedure is designed to account for both an adjustment component to labor market tightness and an 'institutional' component, that is an essential determinant of wage levels in developed countries. In the model, large firms tend to be wage makers, and adjust their wage offer according to their observed level of vacancies and their past wage levels, while small firms tend to be wage takers, and simply use the wage levels prevailing in larger firms of their sector.

\subsubsection{Investment decisions}

Investment goods depreciate at an exogenous, fixed rate. In each period, firms may consider to invest in new machines, both to renew their depreciated capital and to expand their production capacities. Investment is financed with retained earnings and bank loans. In this respect, we assume that firms have a leverage ratio target. Only if their actual leverage lies below this target will the firms consider to invest. If they do so, their investment goods demand will correspond to the number of investment goods that gives the highest net present value of the investment project. This net present value is computed based upon the cost of intermediate goods computed by starting from the cheapest suppliers, and the expected price, wage and real interest rate levels estimated using past average levels.

\subsubsection{Finance through bank loans}

Firms borrow from the bank to finance their production and their investment. Their anticipated wage bill and intermediate goods purchases are financed by nonamortized and short-term loans. Those loans are automatically granted for an exo-

geneously fixed period of time at the risk-free interest rate. Investment is financed 
by amortized loans, granted for a longer period of time (corresponding to the expected lifetime of a machine). In every period, firms repay part of the capital and the due interests on their loans. If a firm is unable to make its due payment, it is downgraded to "doubtful". It will then be given access to an overdraft facility, but at a higher interest rate that includes a fixed risk premium.

\subsubsection{Finance through emission of new shares}

We introduce a stock market in a very rudimentary way by allowing firms with excess indebtedness (compared to their targeted level) to get funds from shareholderhouseholds by issuing new shares. Those potential shareholders are all shareholderhouseholds with excess cash, i.e., whose money balances exceed a fraction of their portfolio value. The price of the firms' shares is set with a Tobin's q ratio equal to unity (i.e., the stock value of the firm is equal to its book value), and the firms issue as many shares as needed to meet their financial needs. Potential shareholders are randomly attributed those shares, in the limit of their available excess cash, but we assume that Ponzi firms (i.e., those whose profits are lower than their interest repayments) are excluded from the financial market, so that non-profitable firms remain exposed to the risk of bankruptcy.

Indeed, if a firm becomes insolvent (i.e., its liabilities exceed its assets), it goes bankrupt and the bank launches the foreclosure procedure. The failed firm's losses are erased and absorbed by the bank's capital ${ }^{5}$, its book value drops to zero, the current shareholders lose their shares, and the bank recapitalizes the bankrupted firm with the excess cash of randomly drawn shareholders, together with new pricing and debt strategies copied on a surviving firm (see below).

Shareholders receive dividends from the firms (and the bank). In each period,

\footnotetext{
${ }^{5}$ In the case where the bank's capital is insufficient to cover the bankrupted firms' losses, the bank goes bankrupt and the simulation breaks off. This remains a rare event, which happens once over the 100 replications of the baseline scenario that we report below.
} 
the firms retain a constant fraction of their average past net profits, and distribute the rest as dividends. The bank has an exogenously fixed target of net worth, and simply distributes as dividends all its net worth beyond that target. The bank's shareholders are households randomly drawn at the beginning of each simulation.

\subsubsection{Market adaptation and production of norms}

The firms update their markup levels and leverage targets using an evolutionary algorithm along the lines of Alchian (1950). In the simplest version of this evolutionary learning process, two operators are essential: an exploration process that constantly introduces new, potentially more profitable strategies into the population of existing strategies, and an exploitation process that propagates the profitable strategies among the population of firms. A natural way to model the exploration process is through idiosyncratic shocks. We assume that, in every period, the firms are subject to small individual shocks that modify their markup and the leverage target, but those shocks are on average zero. Possible economic interpretations of those shocks include small-step innovations by a "trial-and-error" process, or control errors in the implementation of the strategies.

As for the exploitation process, it simply goes hand in hand with the market selection pressure, as the market determines what a profitable strategy is. Strategies of bankrupted firms are considered to be non profitable, and are therefore replaced by more profitable ones. We assume that when a firm goes bankrupt, it does not disappear ${ }^{6}$ but its set of strategies (pricing and debt) is replaced and copied from the strategies of another operating firm. This firm is randomly selected among the non-bankrupted firms of the same sector. A scenario for this process could be the following: an insolvent firm is always purchased by a group of shareholders that

\footnotetext{
6 This assumption avoids the complexities of modeling an entry process of firms, while remaining in line with empirical evidence that suggests that a number of new firms replace a similar number of obsolete firms, without significantly affecting the total number of firms in the market (see, notably, Bartelsman et al. 2003).
} 
put in place a new management team that has been trained in one of the existing operating firms in that sector, and the new managers bring with them the strategies of their former employment.

Exploration and exploitation operate separately in each sector, so that different norms between sectors may emerge from the market selection pressure.

\subsection{The households}

Both workers and shareholders consume the consumption goods. Workers' income comes from labor income (if employed) and shareholder's income from dividends (if any). To smooth their consumption in face of unanticipated income variations, both types of households follow a buffer-stock rule and build precautionary savings. Households cannot borrow and consumption is budget-constrained in every period. We assume that the saving rate out of income from equity ownership is higher than that out of labor income. This assumption has been common when studying income distribution (Marglin 1984). It has found some support in behavioral theories of consumption (see the so-called 'mental accounting' theory (Thaler 1990)).

On the labor market, workers have a reservation wage that they adjust downward if unemployed. On the stock market, shareholders passively buy shares from profitable firms.

\subsection{Matching on markets}

On the labor market, firms with vacancies send job offers to a randomly selected pool of unemployed workers. An unemployed worker only accepts an offer if the offered wage is higher than his reservation wage. The length of the contract is then randomly drawn on a exogenously fixed support.

All goods markets operate on a principle of 'loyalty to reliable suppliers' (Kir- 
man \& Vriend 2000). Buyers keep in memory a list of suppliers from which they fulfill their demand schedule, starting by buying from the cheapest one. The most expensive supplier as well as those who rationed the buyer in the previous period are removed from its list of potential suppliers, and are replaced by randomly drawn suppliers in every period. The selection of suppliers is first based on the capacity to provide goods, which facilitates the creation of supplier-customer networks despite the heterogeneity in firms' sizes. The only difference between the different goods markets is the demand schedule: households' spending decisions are in nominal terms and are budget-constrained, while firms schedule their intermediate and investment good demand in real terms, and borrow from the bank if their cash reserves are insufficient.

Aggregate variables are simply the result of the sum of individual ones across all agents.

\section{Simulation protocol}

\subsection{Calibration}

We devoted some efforts to the calibration of the model. The purpose of this exercise is to reach values for the main variables that are familiar to macroeconomists. In a weak sense, this helps to provide validity to the model since we can find parameters such that those variables reach reasonably realistic values. The successful calibration does not prove that the model structure is right, in the sense that it would faithfully reproduce the true structure of real economies. However, one could argue that if it had been impossible to calibrate the model so as to reach any realistic value, this would had implied a rejection of the model. This calibration exercise is not essential for the dynamic simulations that will be performed and analyzed here. It just adds some credibility to them. We now discuss the main variables we are interested in. 
By construction, in each period, the model respects the two following accounting equations (subscripts $t$ have been dropped for clarity):

$$
\begin{gathered}
r=m \frac{u}{v} \\
\iota=s_{f} m+s_{p}\left(1-s_{f}\right) m+s_{w}(1-m) \Leftrightarrow m=\frac{\iota-s_{w}}{s_{f}+s_{p}\left(1-s_{f}\right)-s_{w}}
\end{gathered}
$$

where $r$ is the gross profit rate, $m$ the profit share, $u$ the rate of capacity utilization, $v$ the capital to capacity output ratio, $\iota$ the investment to income ratio, $s_{f}$ the retention rate of corporations (both firms and bank), $s_{p}$ the propensity to save of the shareholders, $s_{w}$ the propensity to save of the workers.

The propensities to save $s_{f}, s_{p}$ and $s_{w}$ can be derived from the different parameters fixing the behavior of the two types of agents (see Table 7 in Appendix B.2). In the same way, we can approximately control the (long run) investment to income ratio $\iota$ by modifying the technical coefficients for the production function of the machines in each sector. The capital to capacity output ratio is similarly determined by those technical coefficients. As a consequence, we can fix, at least approximately, the (long run) share of profits in our model. However, the utilization rate $u$ and the profit rate $r$ seem to be essentially endogenous. Nonetheless, following a trial and error process on the definition of both the saving behaviors and the production technical coefficients, we succeeded in defining a scenario that exhibits plausible ex post values for each of these variables, as shown in Table 2.

\subsection{Hypotheses}

With this model at hand, we are interested in testing a number of hypotheses. First of all, we want to assess whether our model is viable, and provides a reasonable approximation of a simple economic system. In that respect, ABMs allow us to 


\begin{tabular}{rllll}
\hline \hline Variables & & Baseline & \multicolumn{2}{c}{100 simulations } \\
& & & Mean & \multicolumn{1}{c}{$\sigma$} \\
\hline Retention rate of corporations & $s_{f}$ & 0.4265 & 0.4088 & 0.0261 \\
Propensity to save of shareholders & $s_{p}$ & 0.401 & 0.4382 & 0.0615 \\
Propensity to save of workers & $s_{w}$ & 0.06083 & 0.07273 & 0.0112 \\
Investment to income ratio & $\iota$ & 0.2376 & 0.2532 & 0.0169 \\
Profit share & $m$ & 0.2967 & 0.3040 & 0.0087 \\
Utilization rate & $u$ & 0.8161 & 0.8214 & 0.0099 \\
Capital to capacity output ratio & $v$ & 1.118 & 1.146 & 0.0243 \\
Profit rate & $r$ & 0.2166 & 0.2179 & 0.0027 \\
\hline \hline
\end{tabular}

Table 2 - Observed values of main endogenous variables (on average from $t=500$ to $t=2000)$ in the baseline scenario and in 100 stochastic replications. See Franke (2017) for the discussion of the empirical values of these variables.

separately and simultaneously establish the characteristics of the emerging micro and macro behaviors. Simulation outcomes can then be compared to macro stylized facts - such as co-movement, persistence and cross-correlation patterns in output, debt, etc. - and to micro stylized facts - such as the distribution of the firms' sizes. We refer the reader here to Dosi et al. (2010, 2015) for a state-of-the-art demonstration of empirical validation of an $\mathrm{ABM}$, that we will mostly follow here, and, e.g. Stock \& Watson (1999) for an account of major macroeconomic stylized facts. Therefore, our first hypothesis is the following:

Hypothesis 1 (Validity) The model is able to reproduce itself from period to period in a way that generates patterns that are in line, at least qualitatively, with empirical regularities both at the microeconomic and the macroeconomic levels.

If Hypothesis 1 cannot be rejected by the simulations, then we are interested more specifically in the pricing behaviors that emerge from the interaction between the evolutionary mechanism and market competition:

Hypothesis 2 (Intra-sectoral coordination) Firms coordinate their markup around steady, sector-specific values in a systematic way. 
Hypothesis 2 implies that the average level of the markup across firms of each sector systematically reach the same order of magnitude in all the stochastic simulations, while idiosyncratic shocks will maintain heterogeneity in firms' strategies in every period. If Hypothesis 2 cannot be rejected by the simulation data, we are then interested in the determinants of the values reached by the markups. Given the multi-sector structure of the model, an immediate research question relates to the determinants of the relative levels of the markups, and therefore the relative prices between sectors. Our next hypothesis is guided by a reading of Classical authors and Pasinetti $(1977,1988)$ : the determination of the relative prices has something to do with the amount of labor directly and indirectly required to produce the different goods. Appendix $\mathrm{C}$ derives these corresponding theoretical labor values of the relative prices. Our next hypothesis is then:

\section{Hypothesis 3 (Inter-sectoral hierarchy of markups) Firms set their markups} so that the relative prices between sectors 'gravitate' around the theoretical labor values implied by the technical coefficients of the production functions and the quantities of labor required for the production of the goods.

If we cannot reject Hypothesis 3, an immediate corollary is the question of the adaptability of pricing behaviors when facing exogenous technological shocks that modify permanently the production function in one sector. We therefore come up with the following hypothesis:

Hypothesis 4 (Adaptability) In case of a permanent technological change, the theoretical values of the relative prices are modified, and the firms adjust their markup so that the relative prices gravitate around those new values.

We now discuss the simulation results in Section 4 in light of those four hypotheses. 


\section{Simulation results}

We first present some charts and statistics from a baseline simulation to give an overview of the macroeconomic behavior of the model.

\subsection{Overview}

Delli Gatti et al. (2007) discuss three groups of stylized facts: industrial dynamics, financial facts and business cycles. We discuss the outcomes of our baseline scenario along those three lines.

The model is able to create endogenous business cycles, i.e., fluctuations that are common across sectors. Those fluctuations are persistent as illustrated by the autocorrelation pattern of GDP in the baseline simulation (Figure 2a) ${ }^{7}$.

The observed business cycles display the characteristics of credit cycles as illustrated by Figure 2b: firms' indebtedness leads GDP growth. Therefore, the "leverage engine" induced by the leverage behavior of firms and detailed in Seppecher et al. (2016) induces a pro-cyclical leverage and produces credit cycles in the present multisectoral model as well (see also Figure 4e below). From Figures 3a and 3b as well, S3 appears to be leading, which is in line with an investment multiplier effect. $S 1$ and $S 2$ seem to be coincident, which is easily explained by the mechanical interdependence between the two: demand in $S 1$ arises from the variations in the planned production in S2. Moreover, production in all three sectors appear strongly and positively correlated, with investment $(S 3)$ being more volatile than GDP (sum of the three sectors), and aggregate consumption ( $S 1$ and $S 2)$ being less volatile than GDP.

These cycles impact the labor market (Figures 3c and 3d), and produce an

\footnotetext{
7 Note that we found similar autocorrelation patterns in alternative indicators of aggregate activity, such as consumption or employment. It should also be recalled that our model abstracts from demographic or technological growth, and is therefore a long-run stationary model, as is clear from Figure 3b.
} 


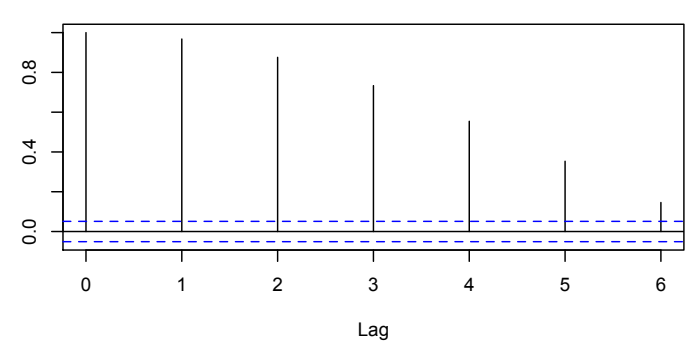

(a) GDP auto-correlation

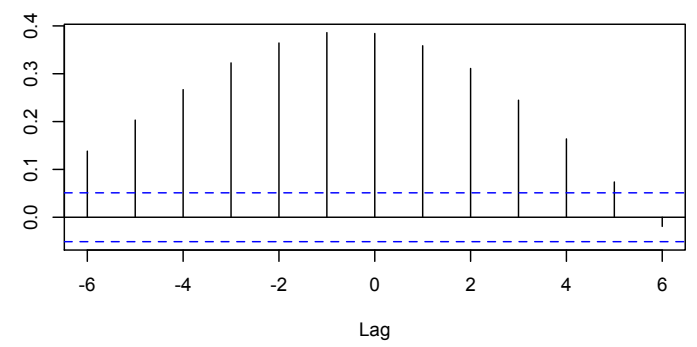

(b) Cross-correlation between GDP and firms' debt

Figure 2 - Statistics of the business cycles in the baseline simulation (time series detrended from a drift).

alternating pattern of periods of unemployment and periods of full employment. Figure 3e displays a downward-slopping Beveridge curve, linking unemployment and vacancies, and Figure 3f a downward-sloping Phillips curve, inversely relating CPI inflation (S2) and unemployment.

Taking a closer look at Figures 3a-3d, we can identify several upturns, associated with a strong rise in potential production in each sector (after period 500, around periods 900, 1300 and 1600, see Figure 3b), followed by downturns associated with a strong increase in unemployment (Figure 3d)- around period 800, periods 1200, 1550 and 1900. Putting in parallel the set of Figures 3 and 4 allows us to shed more light on the cross-correlation patterns between the real and financial variables along those business cycles. For convenience, Figure 4a reports once again the production time series of the baseline simulation next to the other financial indicators. Figure 4c displays the proportion of firms in each sector that become Ponzi firms, as defined by Minsky (1982). Business cycles are closely connected to the fluctuations in the proportion of Ponzi firms, which clearly shows the tight interplay between the financial cycle and the cycle associated with real production (Minsky 1975). In the present case, what we observe is a Minsky-type of cycle, with the number of Ponzi firms and bankruptcy rising in the upturn (see also Figure 4d). Figure 4f reports the returns on assets in each sector, as well as for the bank, and provides 


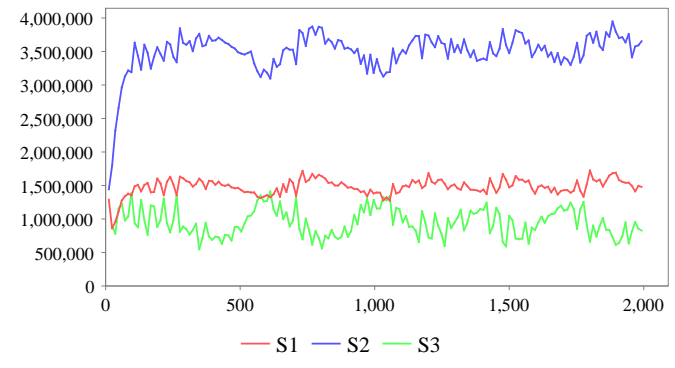

(a) Output

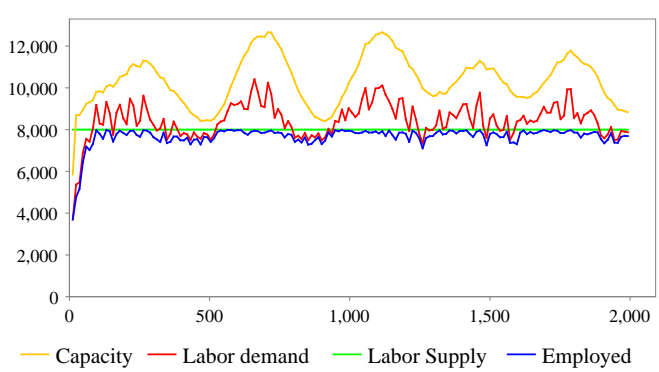

(c) Labor market

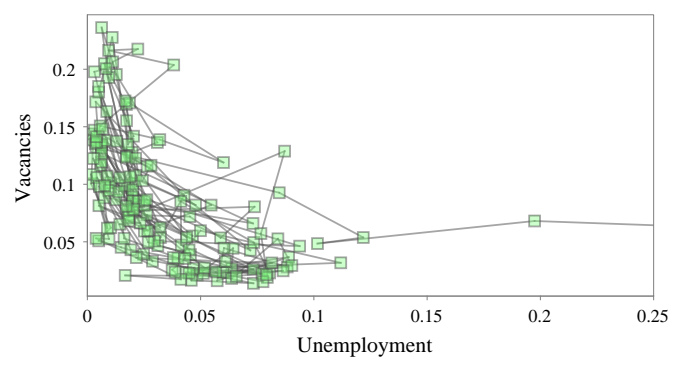

(e) Beveridge curve

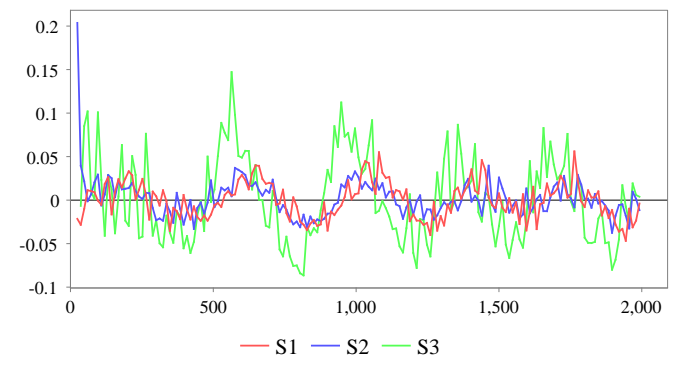

(b) Potential Output Growth

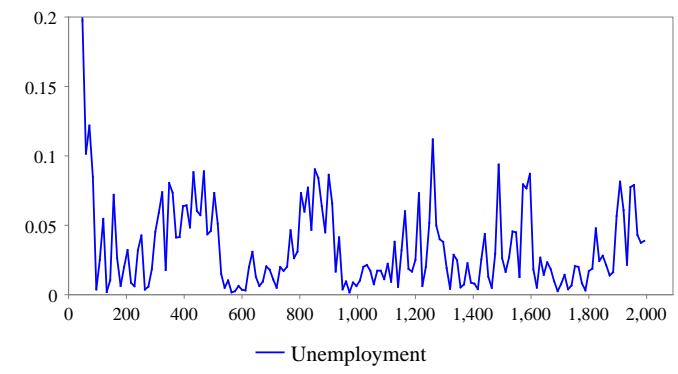

(d) Unemployment

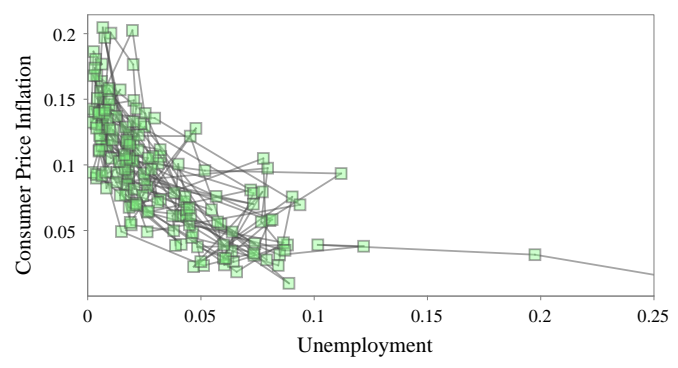

(f) Phillips curve

Figure 3 - Baseline scenario - real indicators

a similar interpretation. Profits in the banking sector are dictated by the interest rates, that is set by the Taylor rule (Figure 4b), and are inversely related to the profits of the firms. Interestingly, we point out that the returns on assets in each of the three industrial sectors are closely connected to each other, which attests the co-movement between all the sectors along the business cycles.

Furthermore, Figure $4 \mathrm{~g}$ shows the target leverage ratios next to the actual leverage ratios of the firms in each sector. Their actual leverage ratio is systematically higher than their target leverage ratio. This excess of debt matches almost perfectly 


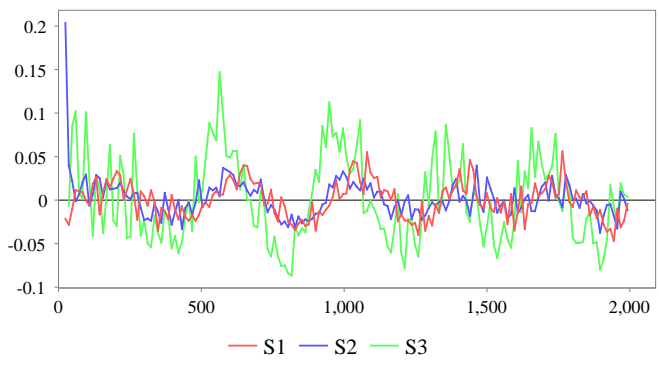

(a) Potential Output Growth

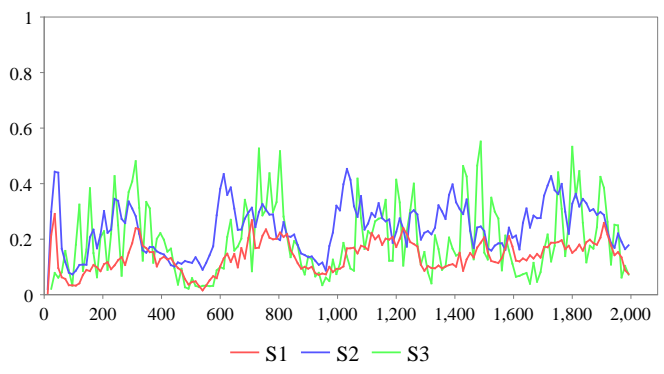

(c) Ponzi firms

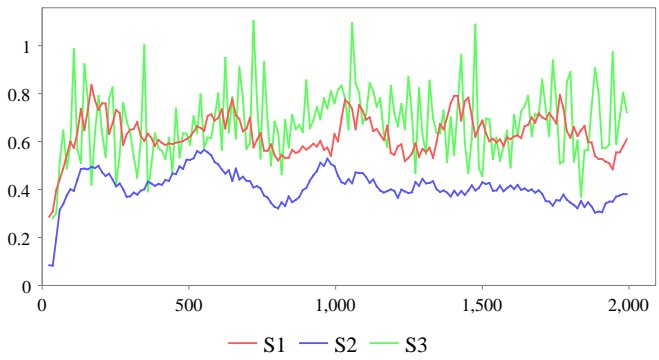

(e) Net worth to sales ratio

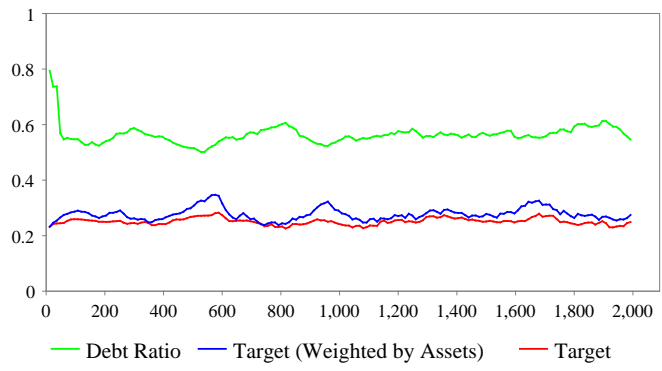

(g) Leverage ratios and targets of firms

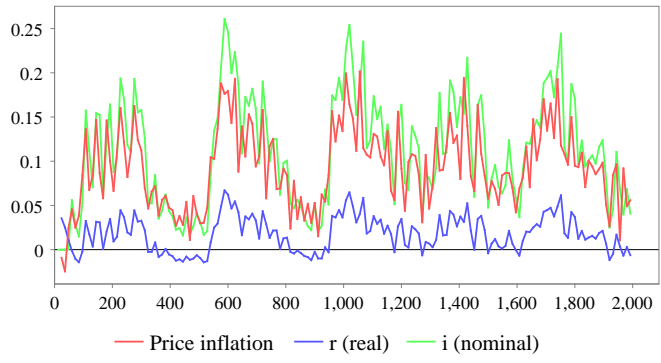

(b) Interest and inflation rates

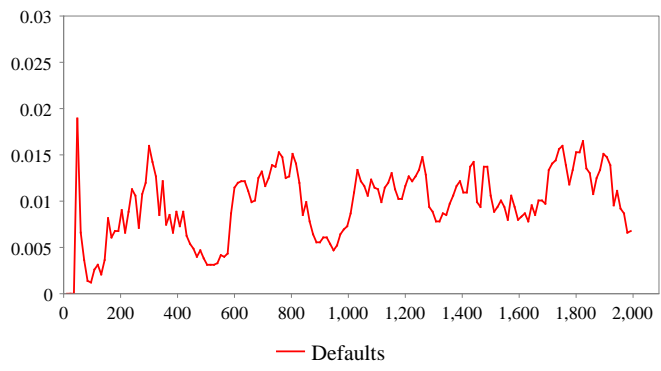

(d) Default rate of the firms (all sectors)

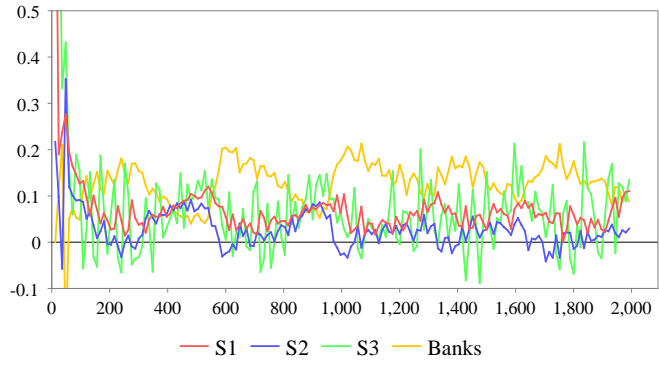

(f) Returns on assets

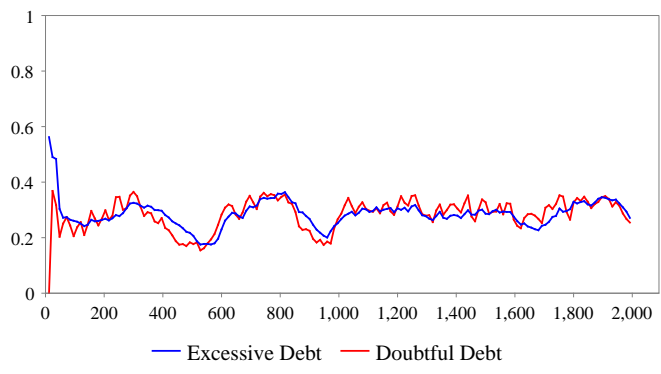

(h) Excessive Debt and Doubtful Debt

Figure 4 - Baseline scenario - financial indicators

the amount of doubtful debts (see Figure 4h). We refer the reader here to Seppecher et al. (2016) for an extensive discussion of the firms' investment and debt behaviors 


\begin{tabular}{|l|l|l|l|l|}
\cline { 2 - 5 } \multicolumn{1}{c|}{} & $\begin{array}{l}\text { Gross profit } \\
\text { rate }\end{array}$ & $\begin{array}{l}\text { Net profit } \\
\text { rate }\end{array}$ & $\begin{array}{l}\text { Bankruptcy } \\
\text { rate }\end{array}$ & Debt ratio \\
\hline All industries & 0.1875 & 0.1173 & 0.1137 & 0.5605 \\
& $(0.0189)$ & $(0.0119)$ & $(0.0129)$ & $(0.0567)$ \\
\hline S1 & 0.2133 & 0.059 & 0.1 & 0.5512 \\
& $(0.0215)$ & $(0.0064)$ & $(0.0125)$ & $(0.0565)$ \\
\hline S2 & 0.1711 & -0.0003 & 0.1422 & 0.5948 \\
& $(0.0174)$ & $(0.0068)$ & $(0.0177)$ & $(0.0613)$ \\
\hline S3 & 0.1987 & 0.0515 & 0.0927 & 0.493 \\
& $(0.0201)$ & $(0.0061)$ & $(0.011)$ & $(0.0508)$ \\
\hline
\end{tabular}

Table 3 - Average values (sd. in brackets) over 100 replications of the baseline scenario, $t \in[500,2000]$, annualized values.

NB: profit rate figures for all industries include the bank.

in a closely related model. In a nutshell, when individual firms try to increase their debt level in order to invest, they collectively create over-capacities and increase their financial fragility, which eventually leads to a sudden downturn. To conclude on the aggregate level of our simulations, Table 3 displays several statistics over 100 replications of the baseline scenario, and shows that they are broadly in line with their empirical counterparts.

ABMs allow us to also look at the distribution of individual characteristics. We then take a look at the microeconomic level of the simulation outcomes. Learning of individual firms combined with market selection has been identified as a major driver of the dynamics with the firms' population (Dosi et al. 2016). Our model turns out to be able to reproduce several stylized facts of this dynamics. Figure 5 reports the cross-sectional distributions of firms' sizes (measured by assets) and firms' amounts of investment (measured as the number of new machines bought divided by the number of existing machines). These distributions are measured across all sectors and the indicators are averaged over the periods 989-1000 (i.e., equivalent to 12 months) of the baseline simulation. Figure 5 a and normality tests suggest that the cross-sectional distributions of the firm (log) sizes are positively skewed (i.e., to the right) and not normal. These tests are carried out in period 1000, 


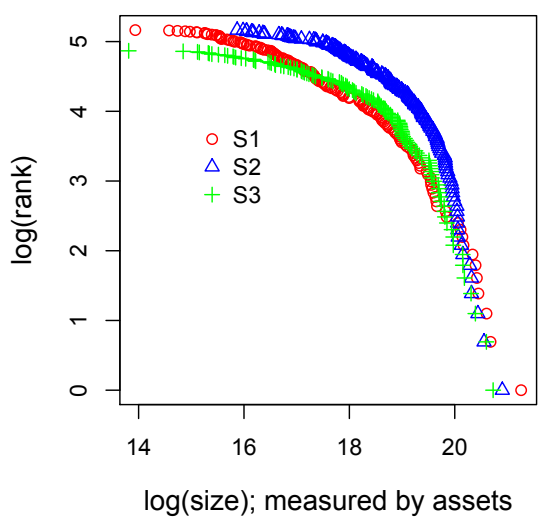

(a) Firms' rank-size distribution

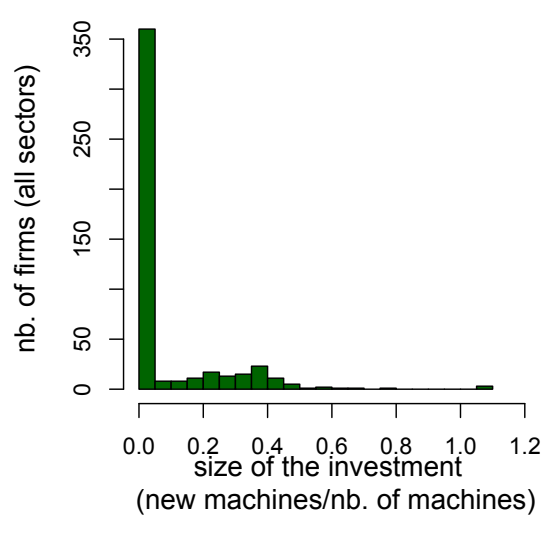

(b) Firms' investment distribution

Figure 5 - Baseline scenario - microeconomic distributions

while firms are initialized with the same size in period 0 . This reveals the strong underlying heterogeneity within the firm population, that is a core mechanism of the evolutionary adaptation processes in our model. Additionally, Figure 5b reports the so-called "lumpiness in investment", i.e., at the same time frame, some firms invest a lot, while most (i.e., roughly $75 \%$ ) do not. ${ }^{8}$

Those results indicate that, even though our exercise is not designed to reproduce quantitatively any stylized fact, the economy that we have modeled is broadly in tune with empirical regularities. We cannot therefore reject our first hypothesis 1 about the viability of our model. But before we turn to the core analysis of the paper, that of pricing decisions, a word of caution is in order. While the average values and correlation patterns of our main variables are no doubt realistic, the same cannot be said of the amplitude of our business cycles. In our view, this is due to several features of the model, namely the absence of the government sector, the very flexible nature of the labor market with only relatively short-term contracts, and, to a lesser extent, the limited number of agents in the model. In the current version of our model, for instance, when workers do not work they have no

\footnotetext{
${ }^{8}$ We recall that the productivity of every machine is time-invariant in our model, therefore we do not discuss cross-sectional differences and evolution in productivity.
} 
income whatsoever and can only spend on the basis of their accumulated savings. The potential negative effect on consumption is strengthened by the relative short work contracts that we have implemented on the labor market. Governments provide an autonomous component of aggregate demand, which stabilizes the economy because this component is relatively independent of previous or current economic activity. An autonomous public sector is indeed sometimes used in ABMs to mitigate aggregate fluctuations (Russo et al. 2014). On a different note, preliminary simulations with a higher number of agents seem to indicate that bigger populations tend to smooth out aggregate fluctuations. For computational time reasons, we use a baseline scenario with a limited number of agents. However, the volatility of the business cycles in the model does not seem to affect our main result about the level and hierarchy of the markups.

\subsection{Endogenous markups}

Figure 6a shows that the simple arithmetic average markups evolve slowly over time. By contrast, the weighted average markups, in which weights are based on the sale values, display a much higher volatility (see Figure $6 \mathrm{~b}$ ). This observation is related to the heterogeneity of firms: the arithmetic average markup levels reflect the fact that individual adaptation through changes in individual markups is a slow process, but abstracts from the crucial dimension of firm size heterogeneity. This simple comparison exercise shows how heterogeneity is a strong vector of collective adaptation of the pricing strategies among firms. For this reason, we will focus on the analysis of weighted average markups, and explain their evolution.

When demand is high, firms with high markups can provide commodities at a high price, and the average markup (weighted by sales) is boosted; conversely, when demand is weak, firms with high markups do not manage to sell their production, 


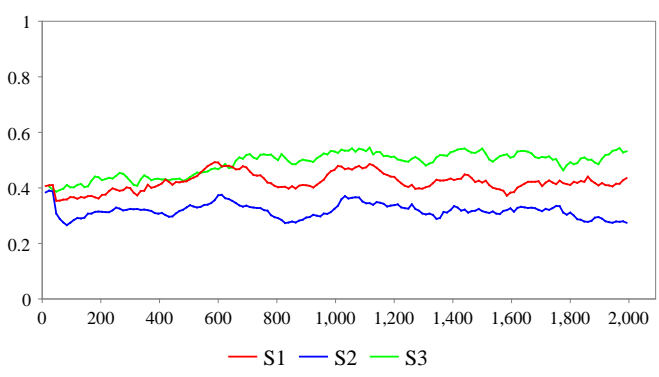

(a) Arithmetic average markups, baseline simulation

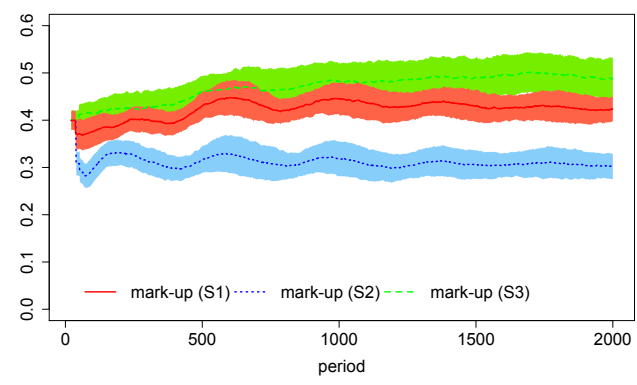

(c) Arithmetic average markups, 100 replications

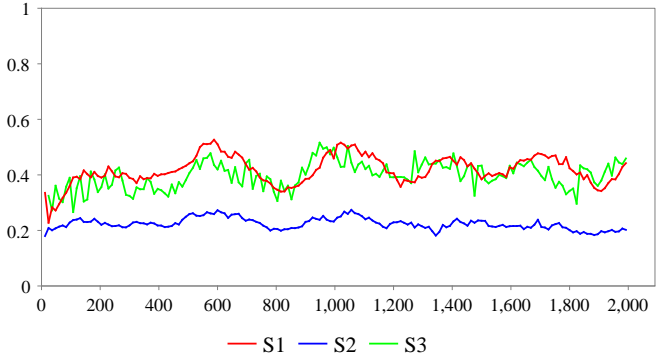

(b) Weighted average markups, baseline simulation

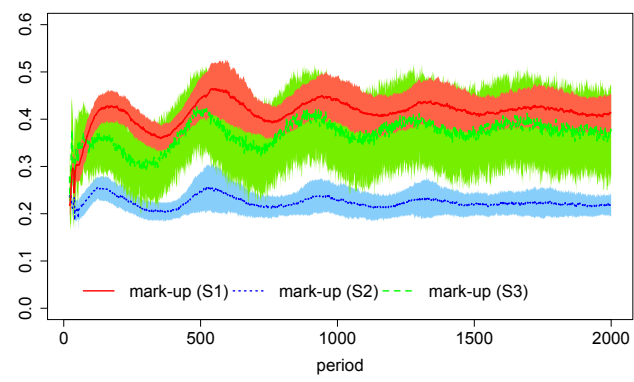

(d) Weighted average markups, 100 replications

Figure 6 - Evolution of markups per sector, arithmetic vs. weighted by sales averages.

and the average markup (weighted by sales) is brought down. ${ }^{9}$ This phenomenon is exacerbated in the medium run by the fact that firms with the more adequate markups will realize more profits than the others, and hence will grow faster, so that their weight becomes more important in the following periods. This phenomenon of collective adaptation does not require any individual adaptation, but only the heterogeneity of the population of firms (the economic equivalent of bio-diversity).

The evolution of weighted average markups being driven by the increase in sale

${ }^{9}$ It should be noted that this pro-cyclical pattern does not contradict the counter-cyclical pattern of markups extensively discussed in Rotemberg \& Woodford (1999). The latter envisions a markup over an increasing marginal cost, caused by diminishing returns, while prices are sticky in the short run, so that the real marginal cost is generally increasing with production. We consider markups over unit costs that are also increasing with production, but this is not because of diminishing returns but rather because nominal wages and the prices of intermediate goods are rising in a boom. Our findings simply say that, in our model, firms are able to increase their prices more than the increase in their unit costs, so that the markup over unit costs (the ratio of the price to unit costs) actually increases with production. Moreover, the discussion in Rotemberg \& Woodford (1999) is set at the aggregate level, and is not incompatible with procyclical adjustments of the markup in individual firms and with the positive relationship between the markup and market shares at the micro level, which our model also reproduces. 
volumes and size of successful firms, i.e., of firms whose pricing and debt strategies allow them to gain market shares, we now take a look at what a "successful" strategy looks like. Figure 7 plots the firms' weighted average markup levels against their return on assets in the baseline simulation in order to illustrate the trade-off that the firms face when deciding upon a pricing strategy. This trade-off is materialized by the emergence of two boundaries: a lower bound (squeeze of profit margins) and an upper bound (loss of market shares). The lower bound (zero) is clearly common to the three sectors, and shows that higher markups provide higher profitability. ${ }^{10}$ However, this relationship is non-monotonic, and the upper bound indicates that increasing the markup comes at the expense of market shares. This upper bound seems lower in 52 , and the scatter plot of markups is more "condensed" towards the bottom than in $S 1$ and $S 3$. This observation tends to indicate that firms in $S 2$ have less margins to increase their markups in face of increasing demand. In other words, price competition seems stronger in $S 2$ than in the other sectors. Figure 8 confirms that intuition. It displays the level of the markups in each sector as a function of market concentration, measured by the normalized Herfindhal-Hirschman index (the higher the index, the higher the concentration). The level of competition is higher in S2, as proved by lower values of the index, while it is comparable in $S 1$ and $S 3$ (despite the same number of firms in $S 1$ and in $S 2$ and fewer firms in $S 3$, see Appendix B.2 for the calibration) As a result, the volatility of the markups is lower in $S 2$ than in $S 1$ and $S 3$, and the scatterplot looks more 'compressed' (the same is true from Figure $8 b) .{ }^{11}$

To sum up so far, we have seen how market competition solves the non-trivial trade-off of pricing decisions. In the short-run, if the heterogeneity of firms and

\footnotetext{
${ }^{10}$ Note that negative markups occasionally arise as a result of the blind idiosyncratic innovation but do not propagate in the population of strategies. Using a strictly positive markup does not affect the results.

11 Additional simulations, not displayed here but available upon request, show that varying the number of firms does not affect the emerging hierarchy of markups.
} 


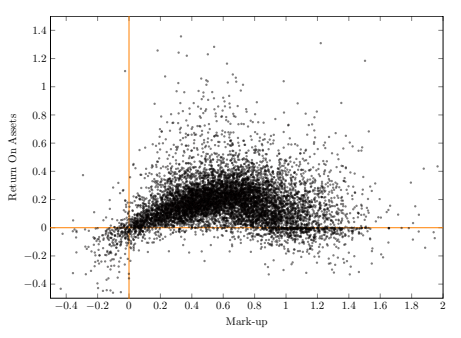

(a) Sector 1

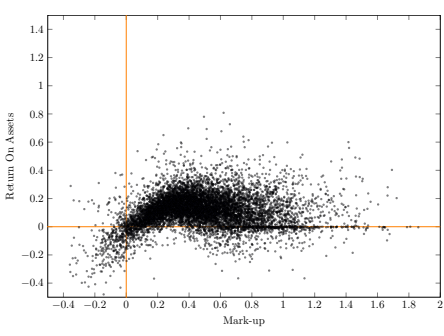

(b) Sector 2

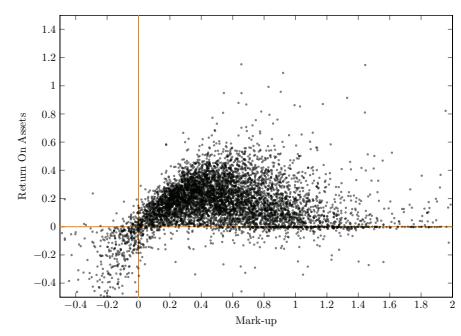

(c) Sector 3

Figure 7 - Firms' mark up distribution against their return on assets, in every 12 periods from $t=1000$ to $t=2000$ in the baseline scenario.

resulting markup strategies is large enough, the set contains the adapted behavior when market conditions and the level of demand change along the business cycles. In the medium run, those adapted behaviors lead to more profitable firms, that grow faster and play a heavier role in the resulting macroeconomic dynamics. This process is self-reinforcing. In the long run, the individual adaptation by selection and imitation forces the firms that have less profitable strategies to adopt observed, more profitable, behaviors or to disappear. It is worth emphasizing that, even though the markups are determined in a quasi-unintentional way in the short-run, meaning that prices are not set by firms in order to match supply and demand, they remain driven by market conditions in the medium run. There is therefore a slow and "noisy" reconciliation between the post-Keynesian theory of administered pricing and the law of demand and supply in the classical theory of price determination.

From all the above observations, we conclude that Hypothesis 2 cannot be rejected: firms coordinate their markup around steady, sector-specific values in a systematic way. Let us emphasize that this outcome is quite remarkable. Indeed, in our model, firms set their price independently from each other, while they are competing for the demand. This competition is based both on their ability to supply the goods (quantity) and their prices (as goods are homogeneous across sectors), as described in Section 2.4. Hence, firms are in a situation of quantity and price competition, without knowing or reacting to each other price levels. While we assume away an 


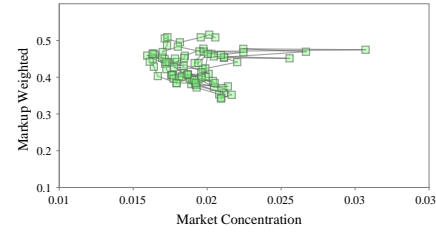

(a) Sector 1

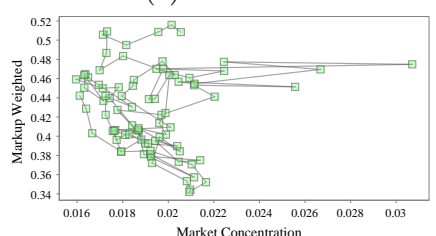

(d) Sector 1

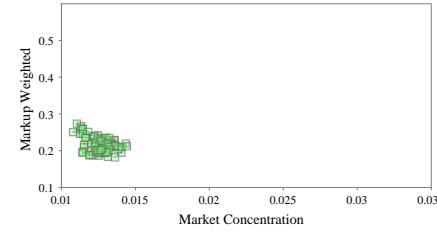

(b) Sector 2

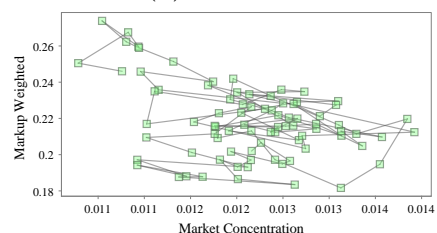

(e) Sector 2

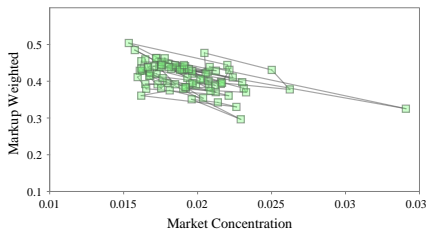

(c) Sector 3

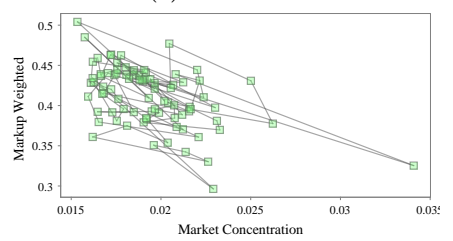

(f) Sector 3

Figure 8 - Baseline scenario - Relationships between the weighted average markup and the Herfindhal-Hirschmann concentration index in each sector between $t=1000$ and $t=2000$. The bottom panel is simply a zoomed representation of the upper panel.

explicit coordination through market forces, we end up observing both intra- and inter-sectoral coordination.

Finally, Figures $6 \mathrm{a}$ and $6 \mathrm{~b}$ reveal a quick evolution towards a hierarchy of sectoral markups that we have not discussed yet. $S 1$ and $S 3$ seem to have comparable levels of markup, while the consumption goods sector (S2) uses significantly lower markups. This structure is a robust feature of the baseline simulation, and is stable despite the business cycles variations (see Figures 6c-6d). This observation reveals the existence of underlying forces driving the respective levels of the sectoral markups. We can now discuss this emerging hierarchy between sectoral markups.

\subsection{Structure of relative prices}

While short-term variations in the markups can be related to the tension between profit seeking and market-share chasing in changing market conditions, we are still left without an explanation of the long-run average level reached by the markups in all replications of the baseline scenario. We therefore test Hypothesis 3, and report 
the average distances over 100 replications of the relatives prices $\frac{P_{1}}{P_{2}}$ and $\frac{P_{2}}{P_{3}}$ to their theoretical values implied by the production technology (see Appendix C). Despite the volatility observed at short frequencies, their long run stability is remarkable, and strikingly gravitates around zero. We observe that the relative prices "gravitate" around the relative "labor values" of the goods, defined as the ratio of the quantities of labor required for the production of these goods. We conclude that Hypothesis 3 cannot be rejected.

As an illustration, Figures 9a-9c display the evolution of the three relative prices in the baseline simulation along with their theoretical relative labor values. It should be noted that the higher volatility observed in $\frac{P_{2}}{P_{3}}$ and $\frac{P_{3}}{P_{1}}$ compared to $\frac{P_{1}}{P_{2}}$ is due to the higher volatility displayed in $S 3$, the investment goods sector.

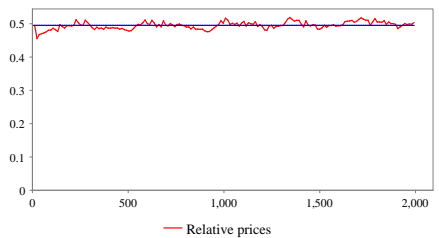

(a) $\frac{P_{1}}{P_{2}}$

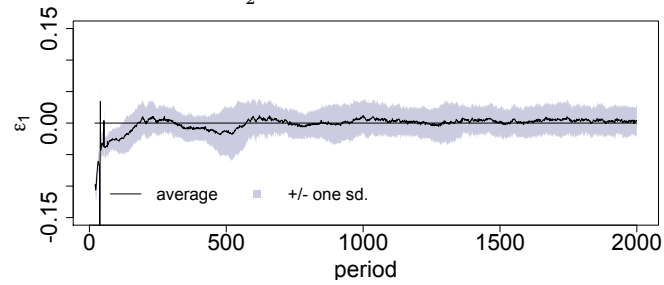

(d) Distance $\epsilon_{1}$ of $\frac{P_{1}}{P_{2}}$ to its theoretical value

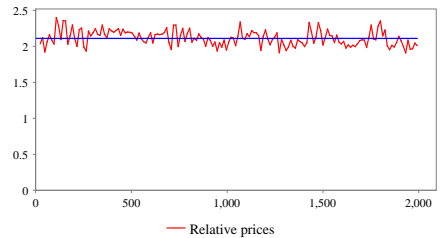

(b) $\frac{P_{2}}{P_{3}}$

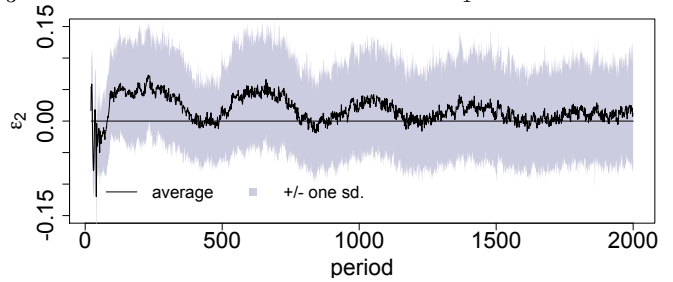

(e) Distance $\epsilon_{2}$ of $\frac{P_{2}}{P_{3}}$ to its theoretical value

Figure 9 - Relative prices compared to their theoretical labor values derived in Appendix $\mathrm{C}$ in the baseline simulation (upper panel), and distances to these benchmark values over 100 replications (bottom panel).

\subsection{Introducing an exogenous technological shock}

Finally, we are interested in the reaction and the ability to adapt to technological shocks by the ecology of firms. 
Starting from the baseline scenario, and using our model as a virtual laboratory, we dramatically change one technical coefficient during the simulation to produce an exogenous technological shock. The coefficient of the productivity of the machines in the consumption goods sector $-p r_{2}-$ is doubled, from $p r_{2}=100$ to $p r_{2}^{\prime}=200$ in period 1000 (as shown in Figure 10a). It should be noted that this new technology is incorporated only in the new machines produced from period 1000 on. As a consequence, the diffusion of the productivity shock displays some inertia. The new, more productive, machines gradually get to replace the old machines as the latter progressively depreciate and disappear.

As S2 becomes more productive, we observe a reallocation of the workforce among the sectors, with a transfer of workers from S2 to $S 1$ and, to a lesser extent, towards $S_{3}$ (Figure 10b). If we are correct in our interpretation of the emergence of the structure of relative prices, this shock will affect the relative prices of $S_{1}$ to $S_{2}$ and of $S_{2}$ to $S_{3}$, but not that of $S_{3}$ to $S_{1}$. An examination of Figures 10c, 10d and $10 \mathrm{e}$ demonstrate that this is indeed the case. After the shock, relative prices are modified and converge towards their new theoretical values. We conclude that Hypothesis 4 cannot be rejected.

Since, by construction, at the micro-economic level, prices are determined through a markup procedure, the change in relative prices consecutive to the technological shock can be explained by a change in the markups. This is indeed what we observe in Figures 10f (baseline simulation) and 10g (average over 100 replications of the simulations). As the technology shock results in a lower theoretical relative price of $S 2$ with respect to $S 1$ and $S 3$, firms in $S 2$ revise downward their markup in the wake of the shock. This result highlights why an ABM is an appealing tool to our research question in particular, and a wide range of complex economic questions in general. The evolution of the markups after the technological shock reveals two causalities: the micro causality linking markups to prices, and the macro causality, 


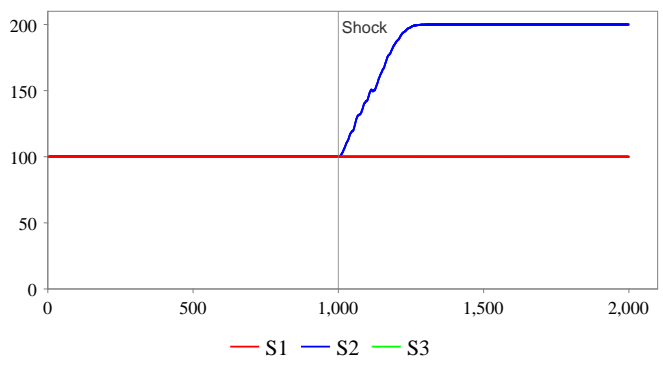

(a) Productivities

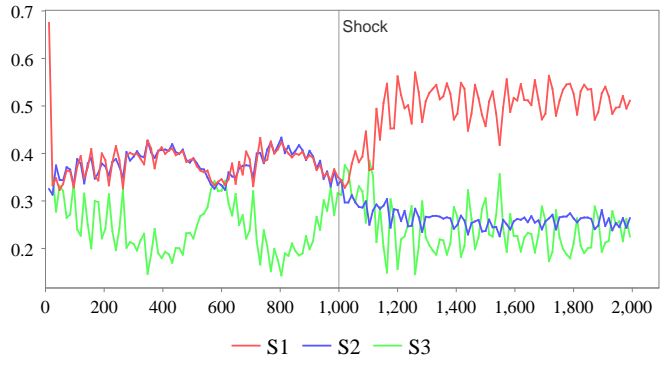

(b) Workforce distribution

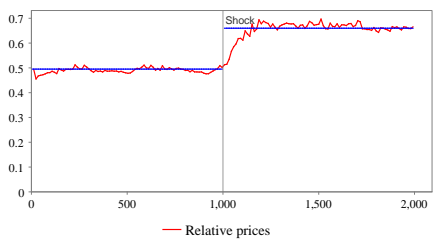

(c) Relative prices : $S 1$ to $S 2$

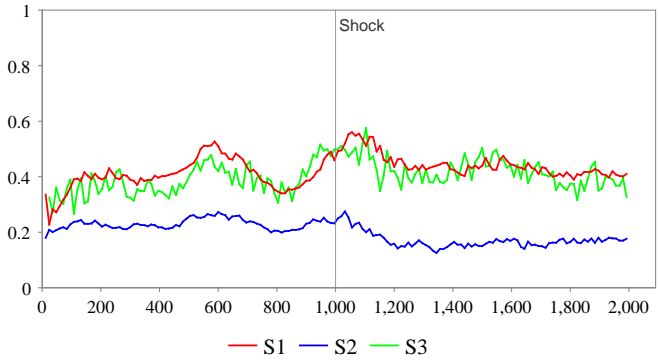

(f) Markups, weighted by sales

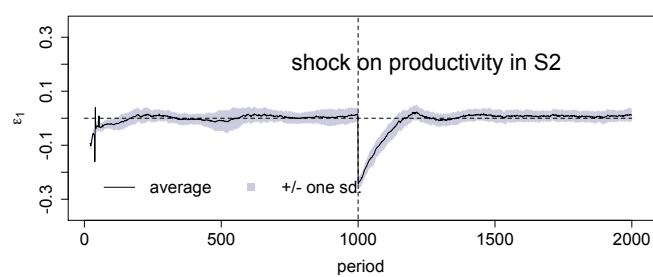

(h) Distance $\epsilon_{1}$ of $\frac{P_{1}}{P_{2}}$ to its theoretical value

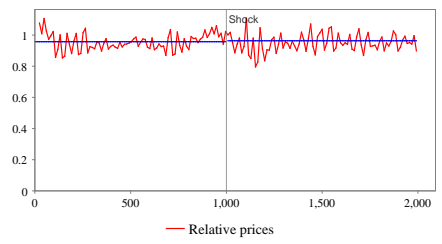

(e) Relative prices : $S 3$ to $S 1$

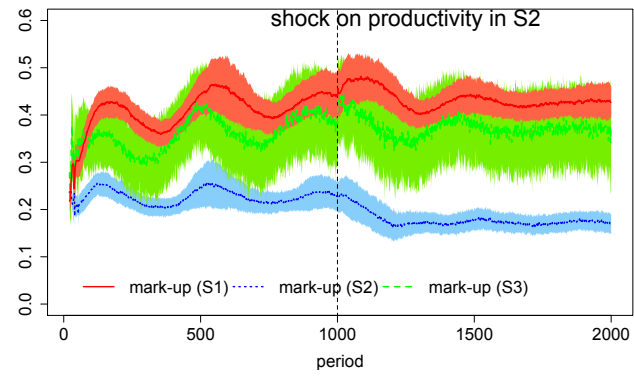

(g) Evolution of markups in each sector.

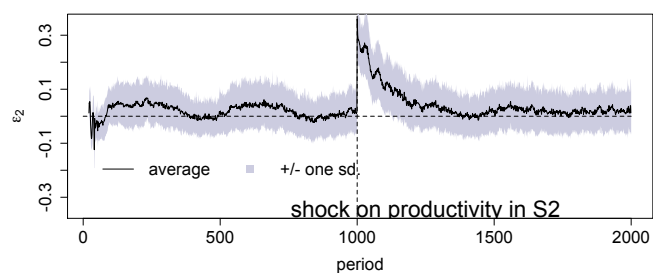

(i) Distance $\epsilon_{2}$ of $\frac{P_{2}}{P_{3}}$ to its theoretical value

Figure 10 - Effects of a technological shock (Sector 2)

from technical coefficients (productivity) to relative prices. Those two causalities are intricate, and operate on different levels, but their interplay is essential to the adaptation of the economic system after a shock.

For the sake of completeness, Figures 11 and 12 show the effects of a technology shock on, respectively, $S 1$ and $S 3$, of the same magnitude as the one on S2 first considered. We only report the average distances of relative prices to their theoretical 
labor values before and after the shocks. We observe exactly the same pattern as following a technological shock in S2: the shock provokes a dramatic disturbance in the system of relative prices but they gradually converge towards their modified theoretical values after the shock, and gravitate around that new attractor (in the sense of dynamical systems). Note that a shock on $p r_{3}$ does not affect $\frac{P_{1}}{P_{2}}$. Therefore, those simulations do not allow us to reject Hypothesis 4.

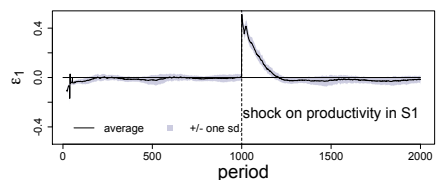

(a) Distance $\epsilon_{1}$ of $\frac{P_{1}}{P_{2}}$

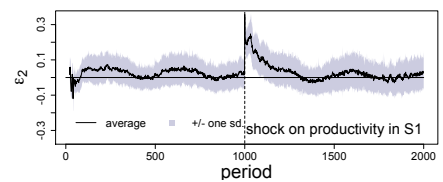

(b) Distance $\epsilon_{2}$ of $\frac{P_{2}}{P_{3}}$

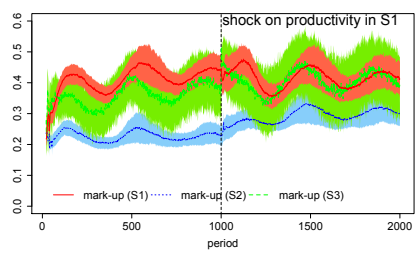

(c) Evolution of the markups

Figure 11 - Effects of a technological shock in $S 1$ across 100 replications of the baseline scenario $\left(p r_{1}=100, p r_{1}^{\prime}=200\right)$.

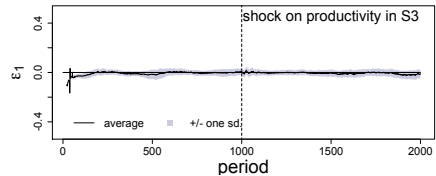

(a) Distance $\epsilon_{1}$ of $\frac{P_{1}}{P_{2}}$

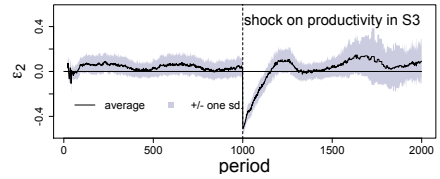

(b) Distance $\epsilon_{2}$ of $\frac{P_{2}}{P_{3}}$

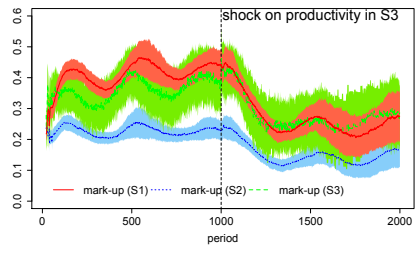

(c) Evolution of the markups

Figure 12 - Effects of a technological shock in $S 3$ across 100 replications of the baseline scenario $\left(p r_{3}=100, p r_{3}^{\prime}=200\right)$.

\section{Interpretation and lessons}

Our model is a complex system. It includes three interrelated production sectors, the households and the bank. These interdependencies are both real (labor and commodities) and monetary (money and debts). Firms in each sector are also in competition with each other for inputs and outlets. In such an environment, the question of the allocation of resources and the relative prices is a non-trivial one. 
Thanks to the radical decentralization principle of ABM, and guided by the observations of Alchian (1950), we let the firms' pricing strategies evolve in an evolutionary manner in such a complex environment, and let the market answer this non-trivial question: how to fix the markups to ensure the survival and the growth of the firms in each sector, and what are the consequences for the relative price levels? The market is a particular form of organization of collective intelligence. Its forces operate like a process of massive and parallel trial-and-errors. Therefore, the market cannot bring a fast and unambiguous reply to the above stated complex problem but, in the long run, we can see the elements of the answer emerge.

We first observe the emergence of a long-run stable and systematic structure of relative prices in the model, with considerable short-run volatility. Although firms set their prices according to idiosyncratic and random innovations on the markup, short-run movements in the markups within the sectors are associated with the permanent trade-off between profit seeking and market-share chasing, in a context of ever-evolving market conditions. In the long run, relative prices appear to "gravitate" around their "labor values", that is, around the ratio of the quantities of labor directly and indirectly required for the goods production in each sector. We therefore succeed in building a model of endogenous formation of markups, interpreted as social norms constantly shaped by the market conditions. This method of endogenous determination of behavioral parameters could be useful every time that the agents in an ABM are confronted with non-trivial choices, resulting in trade-offs, under radical and strategic uncertainty.

Of course, our model relies on restrictive assumptions. One of them is the purely random innovation process and the blind imitation procedure (bankrupt firms imitate any of the surviving firms, independently of their relative level of profits). Abstracting from the individual motivations of firms allows us to highlight the dynamics implied by the sole market competition. This surely constitutes an advantage 
of this approach, as such an observation seems impossible in the real world. However, this does not mean that agents actually behave in such a simple way, which is a criticism of the neo-Schumeterian school towards the Classical evolutionist representation adopted here (Becker et al. 2006, Nelson 2016). Our results are therefore only valid within the theoretical framework that we have considered here, and might be modified if those radical behavioral assumptions have to be relaxed and made more complex. Similarly, the model has a very simplified financial sector, and shareholders do not discriminate between firms, as long as they are profitable. If the model were to be more realistic, capitalists would chose the destination of their excess cash according to some measurements of expected risk and return. We should expect that the most profitable firms and sectors would gather more funds, which could either decrease their leverage or increase their investments and, hence, increase the risk of developing excess capacity. This extension is left for future research.

Another restriction of our framework is the constant number of firms. Even though we have been able to observe concentration or competition effects within the population of firms, this simplification maintains by construction a minimum of market competition, and limits the amount of market power that firms can acquire. This is a deliberate assumption, as our study has focused on the effect of market competition on firms' pricing behavior. An extension of the model could develop a model of entry, and allow for an endogenous dynamics of the population of firms which could potentially lead to sectoral oligopolies. None of these limitations are structural, and each of them are waiting to be pushed away.

Last but not least, it is worth noting that our model is definitively eclectic, featuring ingredients from different and sometimes competing schools of thought. The model includes the post-Keynesian theory of endogenous money and its stock-flow consistent approach; it includes the concerns of Leontief for industrial interdependence; it is consistent with the classical idea that industrial prices gravitate towards 
values that are roughly proportional with the sum of the direct and indirect quantities of necessary labor, as can be found in Sraffa, Pasinetti and Lee; it also relies on Simon's procedural rationality and on Alchian's evolutionary behavior.

Yet, our model is not a chimera. Every ingredient is used because it plays a judicious role in the construction of the model, and results in a coherent synthesis that goes beyond the theoretical borders that fragment economics. This type of models has then the strong advantage of (re)activating the dialog and the exchanges between parallel and competing schools of thoughts in order to contribute to the emergence of a new, alternative paradigm in (macro)economics. 


\section{A Accounting matrices}

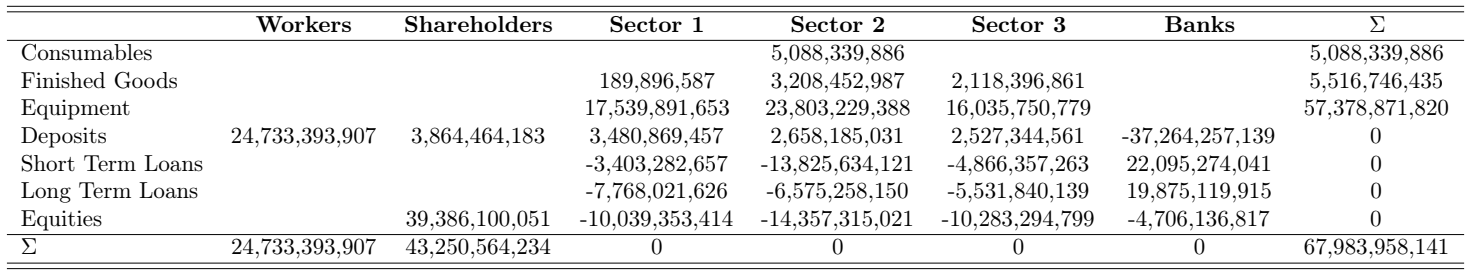

Table 4 - Balance sheet, baseline scenario, $t=1000$

$\stackrel{v}{v}$

\begin{tabular}{|c|c|c|c|c|c|c|}
\hline $\begin{array}{ll}\text { from } & \text { into }\end{array}$ & Sector 1 & Sector 2 & Sector 3 & Workers & Shareholders & $\overline{\bar{\Sigma}}$ \\
\hline Sector 1 & & & & & & \\
\hline Intermediate Goods & & $14,522,923,058$ & & & & $14,522,923,058$ \\
\hline Sector 2 & & & & & & \\
\hline Consumption Goods & & & & $25,954,145,254$ & $2,656,983,706$ & $28,611,128,960$ \\
\hline Sector 3 & & & & & & \\
\hline Equipment Goods & $3,241,516,505$ & $5,072,360,731$ & $3,635,299,389$ & & & $11,949,176,625$ \\
\hline Workers & & & & & & \\
\hline Labor & $9,930,466,516$ & $10,133,161,640$ & $9,235,772,298$ & & & $29,299,400,454$ \\
\hline$\Sigma$ & $13,171,983,021$ & $29,728,445,429$ & $12,871,071,687$ & $25,954,145,254$ & $2,656,983,706$ & $84,382,629,097$ \\
\hline
\end{tabular}

Table 5 - Input-output matrix, baseline scenario, from $t=989$ to $t=1000$ 


\section{B Pseudo-code of Jamel}

\section{B.1 Initialization of the variables (all scenarios)}

\begin{tabular}{|c|c|c|}
\hline Variable & Description & Initial value \\
\hline \hline$k_{j, 0}$ & $\begin{array}{c}\text { capital (i.e., the number of machines per firm, which is also the } \\
\text { maximum number of jobs per firm and per period) }\end{array}$ & 15 \\
\hline$W_{j, 0}$ & targeted leverage & 50 \\
\hline$\ell_{j, 0}^{T}$ & mage offer (monetary units) & $\mathcal{U}[0,0.9]^{12}$ \\
\hline$\theta_{j, 0}$ & $\begin{array}{c}E_{j, 0} \text { of each firm and of the bank are divided in ten equal shares, and } \\
\text { distributed to randomly drawn shareholder-households. }\end{array}$ \\
\hline $\begin{array}{c}\text { Initial } \\
\text { shareholding }\end{array}$ & $\begin{array}{c}\text { All other individual and macroeconomic variables incl. the initial money } \\
\text { balances of households and the total assets and liabilities of the firms and the } \\
\text { bank }\end{array}$ & 0 \\
\hline
\end{tabular}

${ }^{1}$ Random draws are performed for each firm.

Table 6 - All scenarios, including the baseline. 


\section{B.2 Parameter values}

Unless otherwise stated, parameters are the same across households' types (workers

and shareholders) and across firms (sector 1, 2 or 3).

\begin{tabular}{|c|c|c|}
\hline Parameter & Description & Value (all scenarios) \\
\hline \multicolumn{3}{|c|}{ Households } \\
\hline$h_{c}$ & number of shareholders & 1,000 \\
\hline$h_{w}$ & number of workers & 8,000 \\
\hline$\eta_{W}$ & wage adjustment parameter (workers) & 0.01 \\
\hline$g$ & size of the market selection (same as firms) & 20 \\
\hline$\kappa_{w}$ & targeted savings rate (workers) & 0.85 (share) \\
\hline$\kappa_{c}$ & targeted savings rate (shareholders) & 5 (share) \\
\hline$s_{w}$ & propensity to save (workers) & 0.1 \\
\hline$s_{c}$ & propensity to save (shareholders) & 0.8 \\
\hline $\bar{l}_{c}$ & liquidity preference (shareholders) & 0.1 \\
\hline \multicolumn{3}{|c|}{ Firms } \\
\hline$f_{1}$ & number in Sector 1 (intermediate goods) & 175 \\
\hline$f_{2}$ & number in Sector 2 (consumption goods) & 175 \\
\hline$f_{3}$ & number in Sector 3 (investment goods) & 130 \\
\hline$\rho$ & targeted proportion of inventories & $\begin{array}{l}3 \text { (months of production at } \\
\text { full capacity, }\end{array}$ \\
\hline$d^{w}$ & length of employment contracts & $\mathcal{U}[12,36]\left(\right.$ months $\left.^{13}\right)$ \\
\hline$g_{L}$ & $\begin{array}{c}\text { scope parameter of the labor market (wage observations, job } \\
\text { offers sent for each vacancy) }\end{array}$ & 3 \\
\hline$\beta$ & production adjustement & 6 \\
\hline$\delta$ & depreciation rate of inventories & 0.01 \\
\hline$\delta^{W}$ & wage flexibility parameter & 0.025 \\
\hline$s_{f}$ & retention rate & 0.5 \\
\hline$\sigma$ & size of individual innovations & 0.015 \\
\hline $\bar{a}$ & financial threshold for seasoned issues & 0.05 \\
\hline \multicolumn{3}{|c|}{ Parameters of the production functions (Technical coefficients) } \\
\hline$d^{k}$ & lifetime of the machines & $\mathcal{N}(200,36)\left(\right.$ months $\left.^{14}\right)$ \\
\hline$q_{2}$ & $\begin{array}{l}\text { Quantity of intermediate goods to produce } 1 \text { unit of } \\
\text { consumption goods }\end{array}$ & 1 (unit, per period) \\
\hline$k_{1}$ & $\begin{array}{l}\text { Quantity of investment goods to produce } 1 \text { machine in } \\
\text { Sector } 1\end{array}$ & 4000 (units) \\
\hline$k_{2}$ & $\begin{array}{l}\text { Quantity of investment goods to produce } 1 \text { machine in } \\
\text { Sector } 2\end{array}$ & 4000 (units) \\
\hline$k_{3}$ & $\begin{array}{l}\text { Quantity of investment goods to produce } 1 \text { machine in } \\
\text { Sector } 3\end{array}$ & 2500 (units) \\
\hline$p r_{n}$ & Productivity (per one pair worker-machine and period) & $\begin{array}{l}100 \text { (units of goods of the } \\
\text { sector } n \text { ) }\end{array}$ \\
\hline \multicolumn{3}{|c|}{ Bank } \\
\hline$\kappa_{b}$ & capital adequacy ratio (Cooke ratio) & 0.1 \\
\hline$r p$ & risk premium on doubtful debt & 0.04 (monthly) \\
\hline$d^{l}$ & short-run credit length & 12 (months) \\
\hline$d^{L}$ & long-run credit length (= average machine lifetime) & 200 (months) \\
\hline $\bar{\kappa}$ & price adjustement parameter if foreclosure & 0.1 \\
\hline$\phi_{\pi}$ & reaction to inflation (Taylor rule) & 1.5 \\
\hline$\pi^{T}$ & inflation target & $0.02 / 12$ (monthly) \\
\hline \multicolumn{3}{|c|}{ section:model } \\
\hline$T$ & length of the simulations & 2,000 (months) \\
\hline window & memory parameter & 12 (months) \\
\hline
\end{tabular}

Table 7 - All scenarios, including the baseline. 


\section{B.3 Timing of events within a period}

In each period $t, t=1, \ldots, T$ :

\section{Interest rate adjustment:}

$$
i_{t}=\max \left(\phi_{\pi}\left(\tilde{\pi}_{t}-\pi^{T}\right), 0\right)
$$

where $\tilde{\pi}_{t}$ is the price inflation in the consumption goods sector computed over the past window periods.

\section{Fixed capital stock depreciation (straight-line method):}

In each firm $j$, each unit of capital/machine $k_{j, t}$ that is less than $E\left(d^{k}\right)$ month

old is depreciated by $\frac{P_{j, k}}{E\left(d^{k}\right)}$, where $P_{j, k}$ is the purchasing price that firm $j$ paid for machine $k$.

Machines that are older than $E\left(d^{k}\right)$ months and machines that break down before $E\left(d^{k}\right)$ periods are fully depreciated.

\section{Inventories depreciation:}

Each unit of inventories is depreciated at the exogenous rate $\delta$. Its book value is then equal to a fraction $(1-\delta)$ of its values in the previous period.

\section{Lay-off:}

Each worker whose contract ends in period $t$ is laid off.

\section{Individual experimentation:}

For each firm $j$ en each sector $n$ :

- $\ell_{j, t} \hookrightarrow \mathcal{N}(0, \sigma)$ (unless $\left.\ell_{j, t} \notin\right] 0,1\left[\right.$, then $\left.\ell_{j, t}=\ell_{j, t-1}\right)$,

- $\theta_{j, t} \hookrightarrow \mathcal{N}(0, \sigma)\left(\right.$ unless $\theta_{j, t}<-1$, then $\left.\theta_{j, t}=\theta_{j, t-1}\right)$. 


\section{Payment of dividends:}

- Each solvent firm $j$ (i.e., with assets > liabilities)

(a) computes $\tilde{\Pi}_{j, t}$, i.e., its average past profits $\Pi_{j}$ over window periods;

(b) distributes the amount $D_{j, t}=\max \left(\min \left(s_{f} \cdot \tilde{\Pi}_{j, t}, M_{j, t}\right), 0\right)$ as dividends.

- The bank:

(a) computes its targeted level of equities $E_{B, t}^{T}=\left(1-\kappa_{b}\right) \cdot A_{B, t}$ where $A_{B, t}$ represents the total amount of assets of the bank and $\kappa_{b}$ is a parameter.

(b) distributes all its excess equities as dividends: $D_{B, t}=\max \left(E_{B, t}-\right.$ $\left.E_{B, t}^{T}, 0\right)$.

- The corporate (firm or bank) distributes the dividends to its shareholders in proportion to their relative share holding (and, in the case of a firm, within the limits of its available money balances).

\section{Firms' production plan:}

(a) Price setting:

Each firm $j$ sets its price as: $p_{j, t}=\left(1+\theta_{j, t}\right) \cdot u c_{j, t}$, with $u c_{j, t} \equiv \frac{I N V_{j, t}}{i n v_{j, t}}$ the unitary cost of firm $j$, computed as the ratio of the value and the volume of firm $j$ 's inventories.

(b) Wage offer:

Each firm $j$ in each sector $n$ observes a random sample of $g_{L}$ other firms (regardless of the sector). 
- If the observed sample contains a firm $l$ such that $k_{l, t}>k_{j, t}$, then:

$$
\left\{\begin{array}{l}
W_{j, t}=W_{l, t} \\
\bar{W}_{j, t}=W_{j, t}\left(1+\delta^{W}\right) \\
\underline{W}_{j, t}=W_{j, t}\left(1-\delta^{W}\right)
\end{array}\right.
$$

i.e., if firm $j$ can observe a larger firm $l$ than itself, it copies its wage offer.

- Otherwise (i.e., if firm $j$ is the largest firm in the sample), it adjusts its wage offer according to the labor market tightness it has experienced:

- if $\sum_{\tau=1}^{g_{L}} v_{j, t-\tau}>0$

$$
\left\{\begin{array}{l}
\underline{W}_{j, t}=W_{j, t-1} \\
W_{j, t} \hookrightarrow \mathcal{U}\left(W_{j, t-1}, \bar{W}_{j, t}\right) \\
\bar{W}_{j, t}=\bar{W}_{j, t-1}\left(1+\delta^{W}\right)
\end{array}\right.
$$

i.e., if the firm had at least one vacancy over the last $g_{L}$ periods, it increases its wage offer;

- otherwise the firm cuts its wage:

$$
\left\{\begin{array}{l}
\bar{W}_{j, t}=W_{j, t-1} \\
W_{j, t} \hookrightarrow \mathcal{U}\left(\underline{W}_{j, t}, W_{j, t-1}\right) \\
\underline{W}_{j, t}=\underline{W}_{j, t-1}\left(1-\delta^{W}\right)
\end{array}\right.
$$

with $\bar{W}_{j, t}$ the ceiling wage and $\underline{W}_{j, t}$ the floor wage of firm $j$.

\section{(c) Targeted level of production:}

Each firm $j$ in each sector $n$ determines its objective of production $y_{j, t}^{T}$ 
as:

$$
y_{j, t}^{T}=\tilde{s}_{j, t}-\frac{i n v_{j, t}-i n v_{j, t}^{T}}{\beta}
$$

with:

- $\tilde{s}_{j, t}$, its average past sales (in volume, computed over the last window periods),

- $i n v_{j, t}$, its effective inventory volume,

- $i n v_{j, t}^{T}=\rho \cdot p r_{n} \cdot k_{j, t}$, its targeted inventory volume.

\section{(d) Labor demand:}

Each firm $j$ in each sector $n$ :

- Determines its workforce target :

$$
j o b s_{j, t}^{T}=\max \left(0, \min \left(\frac{y_{j, t}^{T}}{p r_{n}}, k_{j, t-1}\right)\right)
$$

where $\frac{y_{j, t}^{T}}{p r}$ is the number of machines firm $j$ aims to utilize to fulfill its targeted level of production.

- If $j o b s_{j, t-1}>j o b s_{j, t}^{T}$ (i.e., if firm $j$ has an excess labor force) firm $j$ lays out the excess labor force according to the principle of last-in first-out.

- Computes its expected wage bill $W B_{j, t}^{T}$.

\section{(e) Financing of the expected wage bill:}

For each firm $j$ in each sector $n$ :

- If and only if $M_{j, t}<W B_{j, t}^{T}$,

- firm $j$ borrows from the bank the amount $W B_{j, t}^{T}-M_{j, t}$ over $d^{l}$ periods at the risk-free interest rate of $i_{t}$ (non-amortized shortterm loan). 


\section{Reservation wages:}

Each worker-household $i$ updates its reservation wage $W_{i, t}^{r}$ :

- If $i$ is unemployed:

$$
W_{i, t}^{r}=W_{i, t-1}^{r}\left(1-\alpha_{i, t} \cdot \eta_{W}\right)
$$

where $\alpha_{i, t}$ is $\mathcal{U}(0,1)$, and $\eta_{W}>0$ is a parameter.

- Otherwise:

$$
W_{i, t}^{r}=W_{i, t-1}
$$

where $W_{i, t-1}$ is the wage earned by household $i$ at the previous period $t-1$.

\section{Labor market :}

(a) Each firm $j$ in each sector $n$ with a labor demand $\left(j o b s_{j, t}^{T}>j o b s_{j, t}\right)$ sends a job offer to a random sample of $g_{L} \cdot j o b s_{j, t}^{T}$ unemployed workers;

(b) Each unemployed worker considers the highest received wage offer and,

- if and only if $W_{j, t} \geq W_{i, t}^{r}$, accepts the job for a duration of $d^{w}$ months; - otherwise, remains unemployed.

Firms' vacancies for period $t$ are then given by $v_{j, t}=j o b s_{j, t}^{T}-j o b s_{j, t} \geq 0$, where $j o b s_{j, t}$ is the number of workers effectively employed in firm $j$ for period $t$ after matching on the labor market.

\section{Production:}

Each firm $j$ in each sector $n$ :

(a) distributes uniformly the hired workers on its machines (one per machine); 
(b) in the sector 2 (consumption goods) only, consumes the corresponding quantities of intermediary goods $q_{2} \cdot p r_{2} \cdot j o b s_{j, t}$;

(c) adds $j o b s_{j, t} \cdot p r_{n}$ goods to firm $j$ 's inventories $i n v_{j, t}$, whose value is then incremented by the production costs (the wage bill and, if $n=2$, the cost of intermediary goods).

\section{Saving/consumption plan of households:}

Each household $i$ in each household sector computes:

(a) its average monthly income over the last window periods, denoted by $\tilde{Y}_{i, t}$;

(b) its actual wealth, composed by

(c) its effective savings $S_{i, t}=M_{i, t}+E_{i, t}-\tilde{Y}_{i, t}$, with $M_{i, t}$ its cash-on-hand and $E_{i, t}$ its equities ( $E_{i, t}$ is always null if the household is a worker);

(d) its targeted savings $S_{i, t}^{T}=\kappa_{h} \cdot \tilde{Y}_{i, t}$;

(e) and its targeted consumption expenditures (nominal demand) as:

$$
C_{i, t}^{T}= \begin{cases}\left(1-s_{h}\right) \tilde{Y}_{i, t} & \text { if } S_{i, t} \leq S_{i, t}^{T} \\ \tilde{Y}_{i, t}+\left(M_{i, t}-M_{i, t}^{T}\right) & \text { otherwise. }\end{cases}
$$

with $\kappa_{h}$ and $s_{h}$ parameters and where $h \in\{\mathrm{w}, \mathrm{c}\}$ ( $w$ stands for the workers and $c$ for the shareholders).

The non-borrowing budget constraint always ensures $C_{i, t} \leq \min \left(C_{i, t}^{T}, M_{i, t}\right)$.

12. Consumption goods market: The suppliers are all firms $j$ of Sector 2 with $i n v_{j, t}>0$ and the buyers are all households (workers and shareholders) with $C_{i, t}^{T}>0$.

(a) Each buyer updates its network of suppliers: 
i. all suppliers with $i n v_{j, t}=0$ are removed from its network;

ii. if there are less than $g$ suppliers in its network, it randomly draws the missing suppliers among the population of firms of Sector 2 with $i n v_{j, t}>0$.

(b) Buyers intend to spend all their consumption budget $C_{i, t}^{T}$ by starting from the cheapest supplier in their network. Once their consumption budget is exhausted, buyers leave the consumption goods market. The same goes for supplyier whose supply is exhausted.

(c) After exiting the consumption goods market, each buyer removes the most expensive supplier from its network.

\section{Intermediary goods demand of firms in Sector 2:}

Each firm $j$ of Sector 2 computes:

(a) its targeted level of input inventories $i n p_{j, t}^{T}=\rho \cdot q_{2} \cdot p r_{2} \cdot k_{j, t}$ (i.e., the amount of input required for $\rho$ months of production at full capacity),

(b) its demand for intermediary goods (in quantity) $i c_{j, t}^{T}$ so as to always keep a volume of intermediary goods necessary to this production:

$$
i c_{j, t}^{T}=\max \left(i n p_{j, t}^{T}-i n p_{j, t}, 0\right)
$$

where $i n p_{j, t}$ is the stock of intermediary goods of firm $j$ after production in period $t$.

\section{Intermediary goods market:}

The suppliers are all firms $l$ of Sector 1 with $i n v_{l, t}>0$ and the buyers are all firms $j$ of Sector 2 with $i c_{j, t}^{T}>0$.

(a) Each buyer $j$ updates its network of suppliers: 
i. removes all suppliers with $i n v_{l, t}=0$;

ii. if there are less than $g$ suppliers in its network, randomly draws the missing suppliers among the population of firms of Sector 1 with $i n v_{l, t}>0$.

(b) Buyers intend to buy the total $i c_{j, t}^{T}$ volume of intermediate goods, by starting from the cheapest supplier in their network.

(c) If, and only if, the cash-on-hand of the buyer is not enough to finance these purchases, the firm borrows the missing amount from the bank over $d^{l}$ periods at the risk-free interest rate of $i_{t}$ (non-amortized shortterm loan).

(d) Once their demand of intermediate goods is exhausted, buyers leave the intermediate goods market. The same goes for supplier whose supply is exhausted.

(e) After exiting the intermediate goods market, each buyer removes the most expensive supplier from its network.

15. Investment goods market : The suppliers are all firms $i$ of Sector 3 with inv $_{i, t}>0$ and the buyers are all firms $j$ of all Sectors 1, 2 and 3 for which:

- $k_{j, t}=0$ (the firm $j$ has no machine, it necessarily invests in one),

- OR $E_{j, t}>E_{j, t}^{T}$, with $E_{j, t}^{T}$, the equity target $=\left(1-\ell_{j, t}^{T}\right) \cdot A_{j, t}$ (in other words, if the effective leverage ratio of firm $j$ is below its targeted ratio $\ell_{j, t}^{T}$ ).

(a) Updating of supplier networks: Each buyer $j$ updates its network of suppliers:

i. removes all suppliers with $i n v_{i, t}=0$;

ii. if there are less than $g$ suppliers in its network, randomly draws the missing suppliers among the population of firms of Sector 3 
with $i n v_{i, t}>0$ and $i \neq j$ (we assume that the firms of Sector 3 cannot buy from themselves).

(b) Investment decisions : With $m$ the number of new machines to acquire:

- If the buyer $j$ has no machine (i.e., $k_{j, t}=0$ ):

- chooses the project $m=1$, for a value $I_{j, t}$.

- Otherwise, the buyer $i$ :

i. computes the vector of the prices of each investment project $\vec{I}=$ $\left\{I_{j, t}(m=1), I_{j, t}(m=2), \ldots\right\}$, with $m=0,1,2, \ldots ;$ (Each investing firm computes the prices of its required investement goods by reviewing the suppliers in its network, starting from the cheapest one.)

ii. given its production target $y_{j, t}^{T}$, its current price $P_{j, t}$, its current wage $W_{j, t}$, the real interest rate $r$, and the vector of prices $\vec{I}$ of each investment project, computes the net present value $N P V_{m}$ of each investment project $m$ until $N P V(m+1)<N P V(m)$;

iii. chooses the project $m$, for a value $I_{j, t}$.

(c) Financing of investment: Each investing firm follows the two-step financing procedure:

i. Each firm $j$ borrows from the bank a fraction $\ell_{j, t}^{T} I_{j, t}$ of its investment goods expenditures $I_{j, t}$ over $d^{L}$ periods at a fixed interest rate of $i_{t}$ (amortized long-term loan).

ii. If, and only if, this loan is not enough to finance the investment (i.e., if $\ell_{j, t}^{T} I_{j, t}+M_{j, t}<I_{j, t}$ ), the firm borrows the missing amount (i.e., $\left.I_{j, t}-\ell_{j, t}^{T} I_{j, t}+M_{j, t}\right)$ with a short-term (amortized) loan (provide that the firm generates enough cash-flow, the short-run loan will be reimbursed shortly and the firm will meet its long-run debt objective). 
(d) After exiting the investment goods market, each firm $j$ removes the most expensive supplier from its network.

\section{Stock market (Seasoned issues):}

(a) The demand side consists of every firm $j$ of all Sectors 1, 2 and 3 that:

- is not Ponzi,

- AND has high enough financial needs (i.e., $E_{j, t}^{T}-E_{j, t}>\bar{a} A_{j, t}$ ).

(b) The supply side consists of each shareholder-household $i$ with excess cash (i.e., with $\left.M_{i, t}>\left(M_{i, t}+E_{i, t}\right) \cdot \bar{l}_{c}\right)$.

(c) Seasoned issues: each firm $j$ in the demand side:

i. randomly selects $g$ shareholders in the supply side of the market;

ii. computes the share price as $p_{j, t}^{\text {share }}=\frac{E_{j, t}}{i s s u e d}$, where issued is the current number of issued shares,

iii. computes the number of new shares to be issued as $\frac{E_{j, t}^{T}-E_{j, t}}{p_{j, t}^{\text {share }}}$.

iv. sells the new shares issued to the selected shareholders at the price $p_{j, t}^{s h a r e}$ in the limit of their available excess cash.

17. Reimbursement of loans: if the firms' available cash-on-hand can cover the due loans, they are paid back. Otherwise, the missing cash-on-hand is borrowed with a short-term loan, at an increased interest rate.

18. Foreclosure (similar to the seasoned issue procedure) : If, and only if, a firm $j$ has become insolvent $\left(A_{j, t}<L_{j, t}\right)$, the bank starts the foreclosure procedure:

(a) The amount of debt $L_{j, t}-A_{j, t}$ is erased, and deducted from the bank's capital, the failed firm's new book value is therefore zero and its shareholders lose their shares; 
(b) New management team: the failed firm copies a markup $\theta_{j, t}$ and a leverage target ratio $\ell_{j, t}$ on a randomly drawn firm, among all the operating firms in the same sector.

(c) The firm $j$ updates $E_{j, t}^{T}$ on the base of its new $\ell_{j, t}$. As $E_{j, t}=0$, the new financial needs of the firm are equal to $E_{j, t}^{T}$.

(d) The firm $j$ draws $g$ potential shareholders among the shareholder-households that have excess cash;

(e) Continuing as the seasoned issue procedure (step 16(c)).

19. Next period. Unless the bank's capital becomes negative (i.e., bank failure and systemic crisis) this process starts all over again for a given length of $T$ periods. 


\section{Assessing the labor values of the three types of commodities}

First we define the direct, indirect and indirect quantities of labor that are necessary to produce a unit of commodity. Our definitions are inspired by those of Pasinetti (1981):

- The direct labor is the amount of the labor that is used in the firm for the production of the commodity;

- The indirect labor is the total amount of labor (direct, indirect and hyperindirect) that has been expended outside the firm, but which was necessary to produce the intermediate goods that were used by the firm for the production of its commodity.

- Hyper-indirect labor is the total amount of labor that was expended to produce the machine that was used by the firm to produce its commodity.

Next, we calculate $l_{1, t} ; l_{2, t} ; l_{3, t}$, the amounts of labor, as defined above, required for the production of one unit of good in each sector S1; S2; S3. Starting from the technical coefficients (see Table 7), we obtain the following:

Sector 3 We start with Sector 3 because the production technology of this sector is fully self-contained, since it produces investment goods with only labour and its own machines. Thus it is possible to calculate the quantity of labour which is necessary to produce one unit of commodity of this sector by only relying on the technical coefficients of this sector.

We wish to calculate $l_{3}$ the quantity of total labour which is necessary on average for the production of one unit of investment good. A machine in Sector 3, the average lifetime of which is $E\left(d^{k}\right)$ periods, during which its average rate of capacity 
utilization was equal to $u_{3}$, will thus produce $p r_{3} u_{3} E\left(d^{k}\right)$ units of investment goods over its lifetime. During this same time period, this production has required the use of $u_{3} E\left(d^{k}\right)$ units of direct labour. To this direct labour one must add the quantity of hyper-indirect labour that was necessary for the production of this machine. The machine was produced with the help of $k_{3}$ units of investment goods, fabricated by the same Sector 3 , through the use of $k_{3} l_{3}$ units of direct labour. Thus we have:

$$
\begin{gathered}
p r_{3} u_{3} E\left(d^{k}\right) \cdot l_{3}=u_{3} E\left(d^{k}\right)+k_{3} l_{3} \\
\left(p r_{3} u_{3} E\left(d^{k}\right)-k_{3}\right) l_{3}=u_{3} E\left(d^{k}\right) \\
l_{3}=\frac{u_{3} E\left(d^{k}\right)}{p r_{3} u_{3} E\left(d^{k}\right)-k_{3}}
\end{gathered}
$$

Sector 1 We move on to Sector 1, since this sector produces intermediate goods with the help of labour and machines. But we now know the total quantity of labor which is necessary to produce the machines coming out of Sector 3. We thus have the elements that are needed to compute the quantity of labour that is necessary for Sector 1 to produce one unit of intermediate good. Over its lifetime, a machine in Sector 1 will normally produce $p r_{1} u_{1} E\left(d^{k}\right)$ units of intermediate commodities, while $u_{1} E\left(d^{k}\right)$ will be the amount of direct labour necessary to produce this amount of intermediate goods. With $k_{1}$ the quantity of investment goods consumed for the creation of this machine, we get:

$$
\begin{gathered}
p r_{1} u_{1} E\left(d^{k}\right) \cdot l_{1}=u_{1} E\left(d^{k}\right)+k_{1} l_{3} \\
l_{1}=\frac{1}{p r_{1}}\left(1+\frac{k_{1} l_{3}}{u_{1} E\left(d^{k}\right)}\right)
\end{gathered}
$$

Sector 2 This is the most difficult sector to deal with since it requires the use of machines made in Sector 3 as well as intermediate inputs that are produced by 
Sector 1. Over its lifetime, a machine in Sector 2 will normally produce $p r_{2} u_{2} E\left(d^{k}\right)$ units of consumption goods; $u_{2} E\left(d^{k}\right)$ will be the amount of direct labour necessary to produce this amount of consumption goods; and $p r_{2} u_{2} E\left(d^{k}\right) j_{2}$ will be the amount of intermediate goods consumed to produce this same amount of consumption goods. With $k_{2}$ the amount of investment goods that are consumed for the creation of this machine, we get:

$$
\begin{gathered}
p r_{2} u_{2} E\left(d^{k}\right) \cdot l_{2}=u_{2} E\left(d^{k}\right)+p r_{2} u_{2} E\left(d^{k}\right) j_{2} l_{1}+k_{2} l_{3} \\
l_{2}=\frac{1}{p r_{2}}\left(1+\frac{k_{2} l_{3}}{u_{2} E\left(d^{k}\right)}\right)+j_{2} l_{1}
\end{gathered}
$$

Computation of relative labor values All the parameters that lead to the computation of the $l_{1}, l_{2}$ and $l_{3}$ values are exogenous, with the exception of the sectorial rates of capacity utilization $u_{1}, u_{2}$ and $u_{3}$. When examining whether prices gravitate around the labour values as defined, we compute the average rate of utilization over the last 1500 periods of the simulation, so as to avoid the first 500 periods which are subjected to the initial shock. In this way, while the economy never reaches an equilibrium, at least it hovers around the stationary state.

On average, from the period $t=500$ to the period $t=2000$ of the baseline simulation, we found:

- $u_{1}=0.9037$

- $u_{2}=0.8255$

- $u_{3}=0.7062$

With these values and those of the technical coefficients in the baseline scenario (see 
Table 7), we compute the relative labour values:

$$
\begin{gathered}
v_{1 / 2}=\frac{l_{1}}{l_{2}}=\frac{\frac{1}{p r_{1}}\left(1+\frac{k_{1} l_{3}}{u_{1} E\left(d^{k}\right)}\right)}{\frac{1}{p r_{2}}\left(1+\frac{k_{2} l_{3}}{u_{2} E\left(d^{k}\right)}\right)+j_{2} l_{1}}=0.495031 \\
v_{2 / 3}=\frac{l_{2}}{l_{3}}=\frac{\frac{1}{p r_{2}}\left(1+\frac{k_{2} l_{3}}{u_{2} E\left(d^{k}\right)}\right)+j_{2} l_{1}}{\frac{u_{3} E\left(d^{k}\right)}{p r_{3} u_{3} E\left(d^{k}\right)-k_{3}}}=2.109582 \\
v_{3 / 1}=\frac{l_{3}}{l_{1}}=\frac{\frac{u_{3} E\left(d^{k}\right)}{p r_{3} u_{3} E\left(d^{k}\right)-k_{3}}}{\frac{1}{p r_{1}}\left(1+\frac{k_{1} l_{3}}{u_{1} E\left(d^{k}\right)}\right)}=0.9575713
\end{gathered}
$$

In the same way, we compute the new relative labor values $v_{1 / 2}, v_{2 / 3}$ and $v_{3 / 1}$ after each technological shock, using the new value of technical coefficients, and the new average rates of utilization observed after the shocks (from $t=1500$ to $t=2000$ ). Table 8 displays the results.

\begin{tabular}{ccccc}
\hline \hline & $\begin{array}{c}\text { Baseline } \\
\text { (no schock) }\end{array}$ & $\begin{array}{c}\text { Shock on } S 1 \\
p r_{1}=200\end{array}$ & $\begin{array}{c}\text { Shock on } S 2 \\
p r_{2}=200\end{array}$ & $\begin{array}{c}\text { Shock on } S 3 \\
p r_{3}=200\end{array}$ \\
\hline$v_{1 / 2}$ & 0.495031 & 0.331545 & 0.659901 & 0.498853 \\
$v_{2 / 3}$ & 2.109582 & 1.566221 & 1.572503 & 4.027636 \\
$v_{3 / 1}$ & 0.957571 & 1.925773 & 0.963674 & 0.497711 \\
\hline \hline
\end{tabular}

Table 8 - Relative labour values, baseline scenario and scenarios with technological shocks

Gravitation Knowing $l_{1}, l_{2}$ et $l_{3}$, at each period $t$, we can compute $\epsilon_{1, t}$ and $\epsilon_{2, t}$, distances from the relative price $\frac{p_{1, t}}{p_{2, t}}$ and $\frac{p_{2, t}}{p_{3, t}}$ to the respective labour values $\frac{l_{1}}{l_{2}}$ and $\frac{l_{2}}{l_{3}}$ :

$$
\begin{aligned}
\epsilon_{1, t} & =\frac{p_{1, t}}{p_{2, t}} \frac{l_{2}}{l_{1}}-1 \\
\epsilon_{2, t} & =\frac{p_{2, t}}{p_{3, t}} \frac{l_{3}}{l_{2}}-1
\end{aligned}
$$




\section{References}

Alchian, A. A. (1950), 'Uncertainty, evolution, and economic theory', The Journal of Political Economy pp. 211-221.

Assenza, T., Delli Gatti, D. \& Grazzini, J. (2015), 'Emergent dynamics of a macroeconomic agent based model with capital and credit', Journal of Economic Dynamics and Control 50, 5-28.

Bartelsman, E., Scarpetta, S. \& Schivardi, F. (2003), Comparative Analysis of Firm Demographics and Survival: Micro-Level Evidence for the OECD Countries, OECD Economics Department Working Papers 348, OECD Publishing.

Becker, M. C., Knudsen, T. \& March, J. G. (2006), 'Schumpeter, Winter, and the sources of novelty', Industrial and Corporate Change 15(2), 353-371.

Bruun, C. (1999), Agent-based Keynesian economics - simulating a monetary production system bottom-up, Technical report, Aalborg University.

Caiani, A., Godin, A., Caverzasi, E., Gallegati, M., Kinsella, S. \& Stiglitz, J. E. (2016), 'Agent based-stock flow consistent macroeconomics: Towards a benchmark model', Journal of Economic Dynamics and Control 69, 375 - 408.

Caiani, A., Russo, A., Palestrini, A. \& Gallegati, M. (2016), Economics with Heterogeneous Interacting Agents: A Practical Guide to Agent-Based Modeling, Springer.

Caverzasi, E. \& Godin, A. (2015), 'Post-keynesian stock-flow-consistent modelling: a survey', Cambridge Journal of Economics 39(01), 157-187.

Cincotti, S., Raberto, M. \& Teglio, A. (2010), 'Credit money and macroeconomic instability in the agent-based model and simulator eurace', Economics: The OpenAccess, Open-Assessment E-Journal 4(26). 
Cohen, K. J. (1960), 'Simulation of the firm', The American Economic Review $\mathbf{5 0}(2), 534-540$.

Coutts, K., Godley, W. \& Nordhaus, W. (1978), Industrial Pricing in the United Kingdom, Cambridge University Press, Cambridge.

Dawid, H., Harting, P. \& Neugart, M. (2014), 'Economic convergence: Policy implications from a heterogeneous agent model', Journal of Economic Dynamics and Control 44, 54-80.

Delli Gatti, D., Gaffeo, E., Gallegati, M., Giulioni, G., Kirman, A., Palestrini, A. \& Russo, A. (2007), 'Complex dynamics and empirical evidence', Information Sciences 177(5), 1204-1221.

Dixit, A. K. \& Stiglitz, J. E. (1977), 'Monopolistic competition and optimum product diversity', The American Economic Review 67(3), 297-308.

Dosi, G., Fagiolo, G., Napoletano, M., Roventini, A. \& Treibich, T. (2015), 'Fiscal and monetary policies in complex evolving economies', Journal of Economic Dynamics and Control 52, 166-189.

Dosi, G., Fagiolo, G. \& Roventini, A. (2010), 'Schumpeter meeting Keynes: A policyfriendly model of endogenous growth and business cycles', Journal of Economic Dynamics and Control 34, 1748-1767.

Dosi, G., Pereira, M. C. \& Virgillito, M. E. (2016), 'The footprint of evolutionary processes of learning and selection upon the statistical properties of industrial dynamics', Industrial and Corporate Change p. dtw044.

Durkheim, É. (1984), The Division of Labour in Society, Macmillan, London.

Fabiani, S., Druant, M., Hernando, I., Kwapil, C., Landau, B., Loupias, C., Martins, F., Matha, T., Sabbatini, R., Stahl, H. \& Stokman, A. (2006), 'What Firms' 
Surveys Tell Us about Price-Setting Behavior in the Euro Area', International Journal of Central Banking 2(3).

Franke, R. (2017), 'A simple approach to overcome the problems from the keynesian stability condition', European Journal of Economics and Economic Policies: Intervention $\mathbf{1 4}(1)$.

Godley, W. \& Lavoie, M. (2007), Monetary Economics, An Integrated Approach to Credit, Money, Income, Production and Wealth, Palgrave Macmillan, Basingstoke.

Hall, R. L. \& Hitch, C. J. (1939), 'Price theory and business behavior', Oxford Economic Papers 2, 12-45.

Kinsella, S., Greiff, M. \& Nell, E. J. (2011), 'Income distribution in a stock-flow consistent model with education and technological change', Eastern Economic Journal 37(1), 134-149.

Kirman, A. P. \& Vriend, N. J. (2000), Learning to be loyal. A study of the Marseille fish market, in 'Interaction and Market structure', Springer, pp. 33-56.

Lavoie, M. (1992), Foundations of Post-Keynesian Economic Analysis, Edward Elgar, Aldershot.

Lee, F. (2011), 'Heterodox microeconomics and the foundation of heterodox macroeconomics', Economía Informa 367, 6-20.

Lee, F. S. (1994), 'From post-Keynesian to historical price theory, part I: facts, theory and empirically grounded pricing model', Review of Political Economy 6(3), 303-336.

Lee, F. S. \& Irving-Lessmann, J. (1992), 'The fate of an errant hypothesis: The doctrine of normal-cost prices', History of Political Economy 24(2), 273-309. 
Leontief, W. W. (1936), 'Quantitative input and output relations in the economic systems of the united states', The Review of Economic Statistics pp. 105-125.

Leontief, W. W. (1937), 'Interrelation of prices, output, savings, and investment', The Review of Economic Statistics pp. 109-132.

Lowe, A. (1952), 'A structural model of production', Social Research pp. 135-176.

Lowe, A. (1955), Structural analysis of real capital formation, in 'Capital Formation and Economic Growth', Princeton University Press, pp. 581-634.

Mandel, A., Landini, S., Gallegati, M. \& Gintis, H. (2015), 'Price dynamics, financial fragility and aggregate volatility', Journal of Economic Dynamics and Control $51,257-277$.

Marglin, S. A. (1984), Growth, Distribution, and Prices, number 155, Harvard University Press.

Mazzoleni, R. \& Nelson, R. R. (2013), 'An interpretive history of challenges to neoclassical microeconomics and how they have fared', Industrial and Corporate Change 22(6), 1409.

Minsky, H. P. (1975), John Maynard Keynes, Columbia UniversityPress, New York.

Minsky, H. P. (1982), Can 'It' Happen Again? Essay on Instability and Finance, ME Sharpe, Armonk.

Nelson, R. R. (2016), 'Behavior and cognition of economic actors in evolutionary economics', Journal of Evolutionary Economics 26(4), 737-751.

Nelson, R. \& Winter, S. (1982), An Evolutionary Theory of Economic Change, Belknap Press. 
Pasinetti, L. L. (1977), Lectures on the Theory of Production, Columbia University Press, New York.

Pasinetti, L. L. (1981), Structural Change and Economic Growth, Cambridge University Press, Cambridge.

Pasinetti, L. L. (1988), 'Growing subsystems, vertically hyper-integrated sectors and the labour theory of value', Cambridge Journal of Economics 12(1), 125-134.

Riccetti, L., Russo, A. \& Gallegati, M. (2015), 'An agent based decentralized matching macroeconomic model', Journal of Economic Interaction and Coordination 10(2), 305-332.

Rotemberg, J. J. \& Woodford, M. (1999), 'The cyclical behavior of prices and costs', Handbook of Macroeconomics 1, 1051-1135.

Russo, A., Riccetti, L. \& Gallegati, M. (2014), Growing inequality, financial fragility, and macroeconomic dynamics: An agent based model, in B. Kaminski \& G. Koloch, eds, 'Advances in Social Simulation: Proceedings of the 9th Conference of the European Social Simulation Association', Springer Berlin Heidelberg, Berlin, Heidelberg, pp. 167-176.

Seppecher, P. (2012), 'Flexibility of wages and macroeconomic instability in an agent-based computational model with endogenous money', Macroeconomic Dynamics 16(s2), 284-297.

Seppecher, P., Salle, I. \& Lang, D. (2016), 'Is the market really a good teacher?'.

Silverberg, G. \& Verspagen, B. (1994), 'Learning, innovation and economic growth: a long-run model of industrial dynamics', Industrial and Corporate Change 3(1), 199-223. 
Simon, H. A. (1979), 'Rational decision making in business organizations', The American Economic Review pp. 493-513.

Sraffa, P. (1960), Production of Commodities: Prelude to a Critique of Economic Theory, Cambridge University Press.

Stock, J. H. \& Watson, M. W. (1999), Business cycle fluctuations in us macroeconomic time series, in J. B. Taylor \& M. Woodford, eds, 'Handbook of Macroeconomics', Vol. 1 of Handbook of Macroeconomics, Elsevier, chapter 1, pp. 3-64.

Thaler, R. H. (1990), 'Anomalies: Saving, fungibility, and mental accounts', The Journal of Economic Perspectives 4(1), 193-205.

Wood, A. (1971), Economic analysis of the corporate economy: A survey and critique, in 'The Corporate Economy', Springer, pp. 37-67. 